\title{
A facile synthesis of Pt carbide nanomaterials and their catalytic applications
}

Junjun Shan ${ }^{1 \# \star}$, Hui Wang ${ }^{\# \#, ~ P i l s u n ~}$ Yoo $^{2}$, Lisa Nguyen', Fu-Kuo Chiang 3 , Sungsik Lee, Peilin Liao ${ }^{2}$, and Jihong Cheng ${ }^{1}$

${ }^{1}$ NICE America Research, Inc, Mountain View, CA 94043, USA

${ }^{2}$ School of Materials Engineering, Purdue University, West Lafayette, IN 47907, USA

${ }^{3}$ National Institute of Clean-and-Low-Carbon Energy, Beijing 102211, China

${ }^{4}$ X-ray Science Division, Argonne National Laboratory, 9700 South Cass Avenue, Lemont, IL 60439, USA

\#These authors contributed equally to this work

*corresponding author: Junjun.Shan@nicenergy.com 


\section{Supporting Information}

Materials preparation. Various supported Pt samples were prepared by relatively simple procedures, involving steps of Pt impregnation, air calcination, and hydrogen reduction. In the step of impregnation, $\mathrm{Pt}\left(\mathrm{NO}_{3}\right)_{2}$ solution was used as the pre-cursor. In the step of calcination, all samples were calcinated in the static air by using a muffle furnace. In the step of reduction, samples were in-situ reduced with pure hydrogen, otherwise noted.

Pt/ZSM-5 catalysts were prepared based on the H-form zeolite. The ammonium form of zeolite, $\mathrm{NH}_{4}$ ZSM-5, with a Si/Al ratio of 15, purchased from Alfa, was first transformed to H-ZSM-5, by calcination in air at $400{ }^{\circ} \mathrm{C}$ for $12 \mathrm{~h}$. Here, ZSM-5 refers to the H-form zeolite with a Si/Al ratio of 15 . In the next step, ZSM-5 powder was mixed with a certain amount of $\mathrm{Pt}\left(\mathrm{NO}_{3}\right)_{2}$ pre-cursor solution to achieve $0.05 \mathrm{wt} \% \mathrm{Pt}$ loading. The mixture was agitated at room temperature (RT) for $1 \mathrm{~h}$ and then heated to $80{ }^{\circ} \mathrm{C}$ in a rotary evaporator for $1 \mathrm{~h}$ to obtain a dry product, followed by a further drying in an oven at $90{ }^{\circ} \mathrm{C}$ overnight. After impregnation, the powder was calcinated in air at $550{ }^{\circ} \mathrm{C}$ for 4 hours, at a heating rate of $5{ }^{\circ} \mathrm{C} / \mathrm{min}$. The product was then pressed and sized to 20x40 mesh. Prior to characterization measurements, the sample was in-situ reduced in hydrogen at $630{ }^{\circ} \mathrm{C}$ for $1 \mathrm{~h}$, at a heating rate of $5{ }^{\circ} \mathrm{C} / \mathrm{min}$, and then was cooled down to RT in hydrogen atmosphere.

We have also used incipient wetness impregnation (IWI) method to prepare some Pt/ZSM-5 samples, followed by the same gas treatments. Our characterization and catalysis data show that these samples prepared thorough IWI exbibit no any significant differences in term of Pt dispersion, nanocluster size, and catalytic activity.

For comparison, Pt/ZSM-5 samples with Pt loading of $0.1 \mathrm{wt} \%, 0.2 \mathrm{wt} \%$, and $0.5 \mathrm{wt} \%$ were also prepared by the similar procedure. As will be demonstrated below, our characterization data show that in the case of $0.1 \mathrm{wt} \% \mathrm{Pt} / \mathrm{ZSM}-5,0.2 \mathrm{wt} \% \mathrm{Pt} / \mathrm{ZSM}-5$, and $0.5 \mathrm{wt} \% \mathrm{Pt} / \mathrm{ZSM}-5$, part of Pt are located on the external surface of zeolite as nanoparticles. Similar to Pt nanoparticles supported on $\mathrm{Al}_{2} \mathrm{O}_{3}$, ethane 
treatments of these nanoparticles on the external surface of zeolite do not lead to the formation of $\mathrm{PtC}_{\mathrm{x}}$ species. Furthermore, we also prepared some samples using zeolite with a higher $\mathrm{Si} / \mathrm{Al}$ ratio, for instance with a Si/Al ratio of 40 and 100-200. Our ethane aromatization and acetylene hydrogenation tests show that these samples with a higher $\mathrm{Si} / \mathrm{Al}$ ratio exhibit much lower catalytic activity. Our CO-DRIFTS measurements also indicate that after reduction the amount of $\mathrm{CO}$ that can adsorb on nanoclusters is significantly reduced, although there is no loss of Pt upon reduction. These observations suggest that the gas accessible to Pt on these samples is largely limited, probably because Pt diffuse to rather deep sites of micropores. Nevertheless, due to above observations, in this work, we focus our attention on the sample of $0.05 \mathrm{wt} \% \mathrm{Pt} / \mathrm{ZSM}-5$ with a Si/Al ratio of 15 . For clarity, Pt/ZSM-5 here refers to the sample with a 0.05 $\mathrm{wt} \% \mathrm{Pt}$ loading, and a Si/Al ratio of 15 , otherwise noted.

In the preparation of $\mathrm{Pt} / \mathrm{Al}_{2} \mathrm{O}_{3}, \mathrm{Al}_{2} \mathrm{O}_{3}$ powder was first mixed with a certain amount of $\mathrm{Pt}\left(\mathrm{NO}_{3}\right)_{2}$ solution to achieve $0.05 \mathrm{wt} \% \mathrm{Pt}$ loading. The mixture was stirred at RT for $1 \mathrm{~h}$ and then heated to $80{ }^{\circ} \mathrm{C}$ for $1 \mathrm{~h}$ in a rotary evaporator to obtain a dry product, followed by a further drying in an oven at $90^{\circ} \mathrm{C}$ overnight. After that, the powder was air calcinated at $550{ }^{\circ} \mathrm{C}$ for 4 hours, at a heating rate of $5{ }^{\circ} \mathrm{C} / \mathrm{min}$. The obtained product was then pressed and sized to 20x40 mesh. Prior to characterization measurements, the sample was in-situ reduced in hydrogen at $630{ }^{\circ} \mathrm{C}$ for $1 \mathrm{~h}$, at a heating rate of $5{ }^{\circ} \mathrm{C} / \mathrm{min}$, and then was cooled down to RT in hydrogen atmosphere.

In the ethane activation procedure, after hydrogen reduction, $\mathrm{Pt} / \mathrm{ZSM}-5$ or $\mathrm{Pt} / \mathrm{Al}_{2} \mathrm{O}_{3}$ was first purged with $\mathrm{He}$ for $10 \mathrm{~min}$. Afterwards, He flow was switch to ethane flow ( $50 \%$ balanced in nitrogen) and kept at $300{ }^{\circ} \mathrm{C}$ for $30 \mathrm{~min}$, otherwise noted. After ethane activation, the sample was cooled down to RT in nitrogen flow, followed by additional $30 \mathrm{~min}$ nitrogen purge prior to characterization measurements.

Materials characterization. After preparation, materials were characterized with Energy-dispersive X-ray Fluorescence Spectroscopy (EDX), X-ray Diffraction (XRD), Scanning Transmission Electron Microscopy (STEM), Dynamic CO Chemisorption, Diffuse Reflectance Infrared Fourier Transform Spectroscopy 
(DRIFTS), Thermal Gravimetric Analysis (TGA), Ultraviolet-visible (UV-vis), Raman Spectroscopy, Xray Absorption Near Edge Structure (XANES), and Extended X-Ray Absorption Fine Structure (EXAFS).

EDX measurements were performed with a Shimadzu EDX-7000 spectrometer. The $0.05 \mathrm{wt} \%$ loading of $\mathrm{Pt}$ on $\mathrm{Pt} / \mathrm{ZSM}-5$ and $\mathrm{Pt} / \mathrm{Al}_{2} \mathrm{O}_{3}$ samples was confirmed by EDX data. XRD patterns of these samples were collected on a Bruker D2 PHASER X-ray diffractometer using nickel-filtered $\mathrm{Cu} \mathrm{K} \alpha$ radiation $(\lambda=1.54056$ Å). The measurements were taken at $30 \mathrm{kV}$ and $10 \mathrm{~mA}$ in a continuous mode and $2 \theta$ range from $10^{\circ}$ to $60^{\circ}$. TGA measurements were carried out by a Shimadzu DTG-60H apparatus.

STEM images of various samples were acquired by JEOL JEM ARM200F with Cs-corrected (probe) at the National Institute of Clean-and-Low-Carbon Energy, and was operated at $200 \mathrm{kV}$ for all analyses. The samples for high-resolution imaging were prepared by dispersing the ground material powder in ethanol and adding a few drops onto copper grids supported on lacey carbon films. Energy-dispersive xray analysis data were obtained using the Oxford X-max 100TLE system. For Pt/ZSM-5 samples, trial imaging experiments allowed the determination of the most appropriate beam conditions to minimize image drifting and loss of the zeolite crystal structure when scanning the sample. Nevertheless, here by using optimized parameters, STEM images were obtained, as illustrated in Figure S1 (Fig. 1a of main text), which shows both Pt nanoclusters and retained zeolite crystal structure. However, imaging with high energy electron beam results serious degradation of the cage structure of the zeolite and significant image shift. ${ }^{18,19}$ Also, Pt species are deposited on the internal surface of ZSM-5. The defocus on Pt species under STEM mode will diffuse the image and alter the precise diameter of nanoparticles. Therefore, STEM may not a suitable technique to determine the precise diameter of nanoclusters supported on zeolite. On average, according to the massive STEM-HAADF images, the Pt cluster size is the range of $0.8-1.8 \mathrm{~nm}$.

In-situ CO dynamic chemisorption was performed through Micromeritics 3FLEX Surface Characterization system, utilizing pulse chemisorption of $\mathrm{CO}$ with a homemade gas loop. Before 
measurements, all samples were in-situ reduced by hydrogen, followed by a He purge and cooling to RT. $10 \% \mathrm{CO}$ (balanced in $\mathrm{He}$ ) was used as the titrating gas at RT.

DRIFTS data were obtained on a Thermo Scientific Nicolet iS50 FTIR Spectrometer and a Harrick Praying Mantis high temperature reaction chamber, with ZnSe windows. The mercury cadmium telluride (MCT) detector cooled by liquid nitrogen was used in all measurements. The surface temperature of the sample bed was calibrated using an external temperature probe. In CO-DRIFTS measurements, CO adsorption on various samples was performed at RT, otherwise noted. $10 \% \mathrm{CO}$ (balanced in $\mathrm{He}$ ) was introduced into the DRIFTS cell at a flow rate of $10 \mathrm{~mL} / \mathrm{min}$ for $10 \mathrm{~min}$. After the flow of $\mathrm{CO}$, a He purge at a flow rate of $30 \mathrm{~mL} / \mathrm{min}$ for $5 \mathrm{~min}$ was applied to remove gas phase $\mathrm{CO}$ in the cell, prior to CO-DRIFTS measurements.

UV-vis data were obtained with a JASCO V750 UV-vis Spectrometer and a Harrick Praying Mantis high temperature reaction chamber. The surface temperature of the sample bed was calibrated using an external temperature probe.

Raman spectroscopy data were obtained with the HORIBA Scientific LabRAM HR Evolution spectrometer at Stanford Nano Shared Facilities. The spectrometer is equipped with three laser excitations (532, 633, and $785 \mathrm{~nm})$, and AIST-NT's SmartSPM Scanning Probe Microscope. During our measurements, the $633 \mathrm{~nm}$ laser excitation was used.

XANES and EXAFS data were obtained at beamline 12-BM at Argonne National Laboratory. XANES and EXAFS data of prepared samples at the Pt $\mathrm{L}_{3}$-edge were collected in fluorescence mode at RT. Approximately 10 consecutive scans were run for each sample to improve the signal-to-noise ratio. XANES and EXAFS data of Pt metal foil and other Pt standards were collected at transmission mode at RT. EXAFS data processing and analysis were performed using the IFEFFIT package.

Catalytic evaluation. Catalytic performance of Pt/ZSM-5, PtC $x / Z S M-5$, and $\mathrm{Pt} / \mathrm{Al}_{2} \mathrm{O}_{3}$ nanomaterials were examined by naphthalene hydrogenation, acetylene hydrogenation, and ethane aromatization reactions. All 
catalytic tests were performed in a fixed-bed flow reactor at atmospheric pressure, a Microactivity Effi reactor system (PID Eng\&Tech). Certain amount of sample was loaded into a quartz reactor tube between two quartz wool plugs. The reactor was heated in a furnace equipped with a temperature controller. The temperature of the catalyst was measured with a K-type thermocouple. The effluent gas was monitored online either by a residual gas analyzer (Hiden HPR-20), or by a gas chromatography (GC), Agilent 7890 GC, equipped with a thermal conductivity detector (TCD) and a flame ionization detector (FID).

In the case of naphthalene hydrogenation, $500 \mathrm{mg}$ catalyst was used, with a total gas flow at $50 \mathrm{~mL} / \mathrm{min}$, containing $\sim 0.1 \%$ of naphthalene vapor and $1 \%$ of hydrogen, balanced in nitrogen. Prior to catalytic measurements, all catalysts were in-situ reduced at $630{ }^{\circ} \mathrm{C}$ for $1 \mathrm{~h}$. The products were analyzed by the Agilent 7890 GC. In the case of acetylene hydrogenation, $500 \mathrm{mg}$ catalyst was used, with a total gas flow at $76 \mathrm{~mL} / \mathrm{min}$, including $2 \mathrm{~mL} / \mathrm{min}$ acetylene, $6 \mathrm{~mL} / \mathrm{min}$ hydrogen, $2 \mathrm{~mL} / \mathrm{min}$ nitrogen, and $66 \mathrm{~mL} / \mathrm{min}$ helium. $\mathrm{Pt} / \mathrm{Al}_{2} \mathrm{O}_{3}$ and $\mathrm{Pt} / \mathrm{ZSM}-5$ catalysts were in-situ reduced at $630{ }^{\circ} \mathrm{C}$ for $1 \mathrm{~h}$, prior to catalytic tests. $\mathrm{PtC}_{\mathrm{x}} / \mathrm{ZSM}-5$ catalyst was prepared by ethane activation at $300{ }^{\circ} \mathrm{C}$ for $30 \mathrm{~min}$, followed by nitrogen purge at RT for $2 \mathrm{~h}$, prior to catalytic tests. The products were analyzed by the Agilent $7890 \mathrm{GC}$. In the case of ethane aromatization, $1 \mathrm{~g}$ catalyst was used, and Gas hourly space velocity (GHSV) of ethane is $1000 \mathrm{~h}^{-1}$. A small amount of nitrogen $(\sim 15 \%)$ was added, as the internal standard. Pt/ZSM-5 catalysts were in-situ reduced at $630^{\circ} \mathrm{C}$ for $1 \mathrm{~h}$, prior to catalytic tests. $\mathrm{PtC}_{\mathrm{x}} / \mathrm{ZSM}-5$ catalyst was prepared by ethane activation at $620^{\circ} \mathrm{C}$ for $10 \mathrm{~min}$, followed by cooling down to $250{ }^{\circ} \mathrm{C}$ in ethane. The products were analyzed both by the Agilent 7890 GC and the Hiden HPR-20 residual gas analyzer.

In this study, every single data point in catalytic measurements was repeated for at least three times at the same conditions. The uncertainties of these measurements were typically below $10 \%$. Only the average value of these results is presented in the paper.

Computational details. Spin polarized density functional theory (DFT) calculations were conducted with Vienna Ab Initio Simulation Package (VASP, 5.4.4 version). ${ }^{35-36}$ Projector augmented wave method 
$(\mathrm{PAW})^{37}$ was adopted, with the $5 \mathrm{~d} 6 \mathrm{~s}$ of $\mathrm{Pt}, 2 \mathrm{~s} 2 \mathrm{p}$ of $\mathrm{C}$ and $3 \mathrm{~s} 3 \mathrm{p}$ of $\mathrm{Al}$ and Si treated as valence electrons. PBE (Perdew-Burke-Ernzerhof) exchange-correlation functional ${ }^{38}$ was used. Energy cutoff was set to 500 $\mathrm{eV}$. Convergence of DFT calculations were achieved when the change in total energy is $<10^{-6} \mathrm{eV}$ in the self-consistent field cycles, and the force per atom is less than $0.025 \mathrm{eV} / \AA ̊$ during geometry optimization.

In the case of nanoclusters, we consider $\mathrm{Pt}_{2 \mathrm{x}}, \mathrm{Pt}_{2 \mathrm{x}} \mathrm{C}_{\mathrm{x}}(\mathrm{x}=5,10,15,20,25)$ and $\mathrm{Pt}_{30} \mathrm{C}_{10}$ cluster models, which have diameters less than or around $1 \mathrm{~nm}$. A combination of effective medium theory (EMT) calculations ${ }^{39}$ with genetic algorithm $(\mathrm{GA})^{40-41}$ as implemented in the Atomic Simulation Environment (ASE) package ${ }^{42}$ was adopted for generation of cluster geometry. The EMT-GA method was used to provide quick search in the large configuration space of $\mathrm{Pt}_{2 \mathrm{x}}$ and $\mathrm{Pt}_{2 \mathrm{x}} \mathrm{C}_{\mathrm{x}}$ clusters, where the clusters can take arbitrary geometries with random distribution of carbon atoms in Pt clusters. Single point DFT calculations were performed to search for the first 100 configurations with lowest energy. The first five configurations with lowest DFT energy were then further optimized with DFT to identify the most stable geometry. The clusters were placed in a cubic box of $22 \AA$ x $22 \AA$ x $22 \AA$. Only Gamma point is included in k-point sampling. Average carbon adsorption energies on $\mathrm{Pt}$ clusters were calculated as $E_{a d} / C=$ $\frac{E\left(P t_{2 x} C_{x}\right)-E\left(P t_{2 x}\right)-x E(C \text { atom })}{x}$, where $\mathrm{E}\left(\mathrm{Pt}_{2 \mathrm{x}} \mathrm{C}_{\mathrm{x}}\right), \mathrm{E}\left(\mathrm{Pt}_{2 \mathrm{x}}\right)$ and $\mathrm{E}(\mathrm{C}$ atom $)$ are the total $\mathrm{DFT}$ energies of $\mathrm{Pt}_{2 \mathrm{x}} \mathrm{C}_{\mathrm{x}}$ cluster, $\mathrm{Pt}_{2 \mathrm{x}}$ cluster and a single $\mathrm{C}$ atom, respectively.

In the case of large nanoparticles, we built a four-layer (2x2) Pt (111) slab model to investigate C adsorption and absorption on the terrace of large Pt nanoparticles. The bottom two layers were fixed at the optimized bulk position. A vacuum of $20 \AA$ was used. 4x4x1 Monkhorst-pack grid was used for k-point sampling. We tested single $\mathrm{C}$ atom adsorption/absorption at sites near FCC hollow, Top, HCP hollow on surface and in subsurface. The $\mathrm{C}$ adsorption energy on Pt (111) slab model was calculated as $E_{a d}^{C}=$ $E($ Pt slab $-C)-E($ Pt slab $)-E($ C atom $)$.

In the case of isolated single Pt atoms, calculations with single Pt atoms supported on ZSM-5 framework were conducted to obtain adsorption energy of one C atom on the single Pt atom. The ZSM-5 
model with Si:Al ratio of 95:1 was adopted, with Al substitution on $\mathrm{T} 1$ site from original $96 \mathrm{Si}$ atoms in the unit cell. The single $\mathrm{Pt}$ atom was situated adjacent to the $\mathrm{Al}$ atom at $\mathrm{T} 1$ site. Van der Waals interaction was described by Grimme's D2 method. ${ }^{43}$ Only Gamma point was included in k-point sampling. The optimized lattice parameters of ZSM-5 $(a=20.03 \AA, b=19.99 \AA, c=13.39 \AA)$ agree well with previous DFT calculation results $(a=20.41 \AA, b=20.14 \AA, c=13.52 \AA),{ }^{44}$ and experimental $\operatorname{report}(a=20.07 \AA, b=19.92 \AA, c=13.42 \AA) .{ }^{45}$

Additional calculation regarding the IR modes related to Pt carbide nanoclusters was also performed. In this calculation, we considered $\mathrm{Pt}_{2 \mathrm{x}} \mathrm{C}_{\mathrm{x}}(\mathrm{x}=5,10,15,20,25)$ cluster models. IR intensities were calculated based on linear-response theory from density functional perturbation theory (DFPT) and Born effective charges. ${ }^{46-50}$

We have also built and tested two additional types of cluster models. One model corresponds to $\mathrm{Pt}_{\mathrm{x}} \mathrm{C}_{60}$ core-shell model, which has the Pt cluster in the core enclosed by $\mathrm{C}_{60}$ as the shell. Another model, indicated as " $\mathrm{Pt}_{\mathrm{x}} \mathrm{C}_{0.5 \mathrm{x}}$ (ring)" has several carbon rings covering part of the Pt cluster. This model is built based on the assumption that only part of Pt cluster in the zeolite is exposed through the channel, and the $\mathrm{C}$ atoms can be accumulated on that part of Pt cluster. We optimize the geometries of both models and calculate their corresponding IR spectra using the same methods as described above.

\section{Supplementary Results and Discussion}

Figure S1 shows STEM images of various supported Pt catalysts. Figure S1a and 1b show images of 0.05 wt $\%$ Pt/ZSM-5 after reduction in Low Angle Annular Bright Field (LAABF) mode and High Angle Annular Dark Field (HAADF) mode, respectively. Figure S1c and 1d show STEM-LAABF and STEM-HAADF images of $0.05 \mathrm{wt} \% \mathrm{Pt} / \mathrm{ZSM}-5$ after ethane activation. Figure S1e and 1f show STEM-LAABF and STEMHAADF images of used $0.05 \mathrm{wt} \% \mathrm{Pt} / \mathrm{ZSM}-5$ after regeneration and reduction. Figure $\mathrm{S} 1 \mathrm{~g}$ and S1h show HAADF-STEM images $0.05 \mathrm{wt} \% \mathrm{Pt} / \mathrm{Al}_{2} \mathrm{O}_{3}$ after reduction. As discussed in the main text, the presence of small Pt nanoclusters is clearly illustrated in STEM images of Pt/ZSM-5 after reduction, with a range of $0.8-1.8 \mathrm{~nm}$. However, the electron beam exposure not only leads to the degradation of the cage structure 
of the zeolite but also the image drift. ${ }^{18,19}$ Therefore, the nanoclusters size determined from STEM images may not be very accurate. Indeed, CO dynamic chemisorption data shown in Figure S2a suggest that the average size of nanoclusters is close to $1 \mathrm{~nm}$.

On the other hand, STEM images of Pt/ZSM-5 after ethane activation in Figure S1c and 1d show similar nanoclusters, suggesting that the agglomeration and decomposition of Pt nanoclusters upon ethane activation can be ruled out. As discussed in main text, upon ethane activation, Pt nanoclusters transform to $\mathrm{PtC}_{\mathrm{x}}$ nanoclusters. However, there is almost no difference between STEM images of Pt nanoclusters and $\mathrm{PtC}_{\mathrm{x}}$ nanoclusters. This is likely due to that $\mathrm{Pt}$ is much heavier than $\mathrm{C}$ so that $\mathrm{C}$ will be invisible in STEM images of the $\mathrm{PtC}_{\mathrm{x}}$ species, and imaging of zeolite supported nanoclusters with high energy electron beam results serious crash of the cage structure of zeolite and significant image shift.

Moreover, similar nanoclusters are also present in STEM images of used Pt/ZSM-5, Figure S1e and 1f, in good agreement with CO dynamic chemisorption results. This further supports that the agglomeration and decomposition of Pt nanoclusters upon ethane activation can be ruled out. In addition, STEM-HAADF images of $\mathrm{Pt} / \mathrm{Al}_{2} \mathrm{O}_{3}$ after reduction, Figure $\mathrm{S} 1 \mathrm{~g}$ and $1 \mathrm{~h}$, demonstrate the presence of large Pt nanoparticles, which is consistent with CO dynamic chemisorption data in Figure S2a.

Figure S2a displays in-situ dynamic CO chemisorption data on bare ZSM-5, $0.05 \mathrm{wt} \% \mathrm{Pt} / \mathrm{ZSM}-5$ after reduction, used $0.05 \mathrm{wt} \% \mathrm{Pt} / \mathrm{ZSM}-5$ after regeneration and reduction, as well as $0.05 \mathrm{wt} \% \mathrm{Pt} / \mathrm{Al}_{2} \mathrm{O}_{3}$ after reduction. The Pt dispersion and average particle size determined from the dynamic $\mathrm{CO}$ chemisorption are listed in Table S1. As agreed with literatures, ${ }^{18,19}$ there is no chemisorption of CO on bare ZSM-5 under our experimental conditions. The dynamic chemisorption behaviors of CO on Pt/ZSM-5 after reduction and $\mathrm{Pt} / \mathrm{Al}_{2} \mathrm{O}_{3}$ after reduction are very different. As listed in Table S1, for $\mathrm{Pt} / \mathrm{Al}_{2} \mathrm{O}_{3}$, Pt dispersion is approximate $20 \%$, and Pt mainly forms nanoparticles with the average particle size at $\sim 6 \mathrm{~nm}$. Whilst, for Pt/ZSM-5, Pt dispersion is at $\sim 100 \%$, and Pt forms small nanoclusters with the cluster size smaller or close to $1 \mathrm{~nm}$. Similarly, for used Pt/ZSM-5, the near 100\% Pt dispersion persists, suggesting the presence of similar small 
Pt nanoclusters. Thus, the formation of Pt carbide does not cause any significant agglomeration or decomposition of nanoclusters. In addition, the much larger peak width in the case of Pt/ZSM-5 suggest that these Pt nanoclusters are likely located within micropores of zeolite, forming encapsulated Pt nanoclusters..$^{51}$

Figure S2b shows XRD patterns of bare ZSM-5, and $0.05 \mathrm{wt} \% \mathrm{Pt} / \mathrm{ZSM}-5$ after reduction, as well as the same catalyst after ethane aromatization reaction and following regeneration. XRD patterns of $0.05 \mathrm{wt} \%$ Pt/ZSM-5 after reduction show no observable difference compared with XRD patterns of bare ZSM-5, suggesting neither the impregnation nor the following calcination and reduction steps cause any changes of the ZSM-5 crystal structure. Furthermore, XRD patters of used $0.05 \mathrm{wt} \% \mathrm{Pt} / \mathrm{ZSM}-5$ after regeneration are preserved. Thus, ethane aromatization reaction, in other words the formation of Pt carbide does not alter the lattice structure of ZSM-5. Moreover, XRD patterns of $0.05 \mathrm{wt} \% \mathrm{Pt} / \mathrm{Al}_{2} \mathrm{O}_{3}$ after various treatments (not shown here), also demonstrate that Pt impregnation and following gas treatments do not cause any significant changes of the support. In addition, XRD patterns of Pt/ZSM-5 and $\mathrm{Pt} / \mathrm{Al}_{2} \mathrm{O}_{3}$ also show that no diffraction peaks related to Pt oxide or metallic Pt species are present, ${ }^{52}$ which is expected at such small loading of Pt.

Figure $\mathrm{S} 3$ shows normalized $\mathrm{Pt} \mathrm{L}_{3}$-edge XANES spectra of $0.05 \mathrm{wt} \% \mathrm{Pt} / \mathrm{ZSM}-5$ after calcination, 0.05 wt $\%$ Pt/ZSM-5 after reduction, $0.05 \mathrm{wt} \% \mathrm{Pt} / \mathrm{ZSM}-5$ after ethane activation, $0.05 \mathrm{wt} \% \mathrm{Pt} / \mathrm{Al}_{2} \mathrm{O}_{3}$ after reduction, $0.05 \mathrm{wt} \% \mathrm{Pt} / \mathrm{Al}_{2} \mathrm{O}_{3}$ after ethane treatment, as well as various Pt standards. XANES data of all Pt/ZSM-5 and Pt/ $\mathrm{Al}_{2} \mathrm{O}_{3}$ samples were collected at $\mathrm{RT}$ in fluorescence mode. Approximately 10 consecutive scans were collected for each sample to improve the signal-to-noise ratio. Three standard samples $\mathrm{PtO}_{2}$, $\mathrm{PtCl}_{2}$, and $\mathrm{Pt}$ foil were used as reference. XANES data of these standards were collected in the transmission mode at RT.

XANES spectrum of $0.05 \mathrm{wt} \% \mathrm{Pt} / \mathrm{ZSM}-5$ after calcination clearly shows that Pt species in Pt/ZSM-5 after calcination are not metallic but in cationic state, likely $\mathrm{Pt}^{4+}$. As will be discussed below, our data 
suggest that $\mathrm{Pt}$ is indeed in the presence of isolated single cations. On the other hand, the absorption edge of Pt/ZSM-5 after reduction, (Fig.1c in main text) shows the white line with a slightly higher intensity than Pt foil. Similar $\mathrm{Pt}_{3}$-edge white line with a slightly higher intensity was observed in several studies of encapsulated small Pt nanoclusters. ${ }^{17,53}$ Thus, our XANES spectra are consistent with the presence of encapsulated Pt nanoclusters located within micropores of ZSM-5. Furthermore, as discussed in main text, the appearance of a new pre-edge peak centered $11545 \mathrm{eV}$ for XANES spectrum of Pt/ZSM-5 after ethane activation at $300{ }^{\circ} \mathrm{C}$ for $30 \mathrm{~min}$, suggests the formation of encapsulated $\mathrm{PtC}_{\mathrm{x}}$ nanoclusters upon ethane activation. Moreover, for $0.05 \mathrm{wt} \% \mathrm{Pt} / \mathrm{Al}_{2} \mathrm{O}_{3}$ after reduction, XANES spectrum is highly resembling Pt foil, suggesting the formation of metallic Pt nanoparticles. In addition, for $0.05 \mathrm{wt} \% \mathrm{Pt} / \mathrm{Al}_{2} \mathrm{O}_{3}$ after ethane treatment, the absence of the pre-edge peak centered at $11545 \mathrm{eV}$, indicates that there is no formation of $\mathrm{Pt}$ carbide upon ethane treatment on large Pt nanoparticles.

Figure S4 shows Pt L3-edge EXAFS data of 0.05 wt\% Pt/ZSM-5 after calcination, 0.05 wt\% Pt/ZSM5 after reduction, and $0.05 \mathrm{wt} \% \mathrm{Pt} / \mathrm{ZSM}-5$ after ethane activation, as well as $\mathrm{PtO}_{2}$ and $\mathrm{Pt}$ foil standards. EXAFS data of all Pt/ZSM-5 samples were collected at RT in fluorescence mode. Approximately 10 consecutive scans were collected for each sample to improve the signal-to-noise ratio. EXAFS data of two standards were collected in the transmission mode at room temperature. The Quantitative analyses for these EXAFS data are shown in Table S2. The analyses reveal that there is no distinct Pt-Pt bonding in the sample of $0.05 \mathrm{wt} \% \mathrm{Pt} / \mathrm{ZSM}-5$ after calcination, indicating the presence of isolated Pt cations, likely within micropores of zeolite. Moreover, the relatively short bond length of Pt-O bond in Pt/ZSM-5 after calcination, $1.98 \pm 0.02 \AA$, compared to the $2.57 \AA$ \& bond length of Pt-O bond in zeolite supported Pt nanoclusters (will be discussed below), confirms that the Pt-O bonds in Pt/ZSM-5 after calcination are not originated from zeolite supported Pt nanoclusters, but from isolated single Pt cations.

In the case of $0.05 \mathrm{wt} \% \mathrm{Pt} / \mathrm{ZSM}-5$ after reduction, our analysis suggests that the EXAFS spectrum cannot be fitted with two regular Pt-O $(\sim 2 \AA)$ and Pt-Pt $(\sim 2.7 \AA)$ scattering paths. It has been reported that the bond length of Pt-O bond between zeolite supported Pt nanoclusters and the zeolite frameworks is at 
2.5 $\AA,,^{17,54}$ much larger than Pt-O bonds in $\mathrm{PtO}_{2}$ and isolated single Pt cations. Thus, the additional Pt-O scattering path at $\sim 2.5 \AA$ was also included in the fitting of $0.05 \mathrm{wt} \% \mathrm{Pt} / \mathrm{ZSM}-5$ after reduction. As shown in Figure 4, after including this additional Pt-O scattering path, the EXAFS spectrum of $0.05 \mathrm{wt} \% \mathrm{Pt} / \mathrm{ZSM}$ 5 after reduction can be reasonably fitted. As listed in Table S2, there are two different Pt-O bonds, namely $\mathrm{Pt}_{1}-\mathrm{O}$ and $\mathrm{Pt}_{\mathrm{n}}-\mathrm{O}$, with bond length at $2.05 \pm 0.04 \AA$ and $2.57 \pm 0.05 \AA$ respectively. The $\mathrm{Pt}_{1}-\mathrm{O}$ bond is likely owing to the presence of isolated Pt cations, probably also Pt dimers/trimers. Whilst, $\mathrm{Pt}_{\mathrm{n}}-\mathrm{O}$ can be attributed to the Pt-O bond of Pt nanoclusters with framework oxygen atoms in zeolite. Moreover, the coordination number of Pt-Pt contribution is approximately $5.4 \pm 0.8$, which corresponds to nanocluster size close or less than $1 \mathrm{~nm} .{ }^{55}$ Therefore, our EXAFS data are consistent with the formation of near sub-nanometric Pt nanoclusters.

On the other hand, the EXAFS fitting of $0.05 \mathrm{wt} \% \mathrm{Pt} / \mathrm{ZSM}-5$ after ethane activation suggests that the coordination number of $\mathrm{Pt}_{\mathrm{n}}-\mathrm{O}$ bond considerably increase. However, if one considers that after ethane activation $\mathrm{Pt}-\mathrm{C}$ bonds are formed, it seems that the increase of the coordination number of $\mathrm{Pt}_{\mathrm{n}}-\mathrm{O}$ bond, is more likely due to the overlap of this bond with $\mathrm{Pt}-\mathrm{C}$ bonds, which may have bond length close to $\mathrm{Pt}_{\mathrm{n}}-\mathrm{O}$ bond. It has been observed that for isolated single Pt atoms embedded in carbon matrix, the bond length of formed Pt-C bonds is $2.75 \AA .^{22}$ Thus, the formed Pt-C bond in $\mathrm{PtC}_{\mathrm{x}} / \mathrm{ZSM}-5$ may have similar bond length. However, the rather small difference in the length of $\mathrm{Pt}-\mathrm{C}$ bond with $\mathrm{Pt}_{\mathrm{n}}-\mathrm{O}$ bond and $\mathrm{Pt}-\mathrm{Pt}$ bond makes it impossible to differentiate $\mathrm{Pt}-\mathrm{C}$ contribution with $\mathrm{Pt}_{\mathrm{n}} \mathrm{O}$ and $\mathrm{Pt}-\mathrm{Pt}$ contributions. Therefore, as listed in Table S2, Pt-C scattering path has not been included in the fitting of the EXAFS spectrum, but may have its contributions in $\mathrm{Pt}_{\mathrm{n}}-\mathrm{O}$ or $\mathrm{Pt}-\mathrm{Pt}$ scattering paths.

The presence of $\mathrm{Pt}$ within micropores of zeolite is also supported by the different catalytic performance of Pt nanoclusters in two hydrogenation reactions, namely naphthalene hydrogenation and acetylene hydrogenation. In the case of naphthalene hydrogenation, the catalytic activities of $0.05 \mathrm{wt} \% \mathrm{Pt} / \mathrm{ZSM}-5$, $0.1 \mathrm{wt} \% \mathrm{Pt} / \mathrm{ZSM}-5,0.2 \mathrm{wt} \% \mathrm{Pt} / \mathrm{ZSM}-5,0.5 \mathrm{wt} \% \mathrm{Pt} / \mathrm{ZSM}-5$, and $0.05 \mathrm{wt} \% \mathrm{Pt} / \mathrm{Al}_{2} \mathrm{O}_{3}$ were examined. 500 mg catalyst was used, with a total gas flow at $50 \mathrm{ml} / \mathrm{min}$, containing $\sim 0.1 \%$ of naphthalene vapor and $1 \%$ 
of $\mathrm{H}_{2}$. The catalysts were first in-situ reduced in hydrogen followed by nitrogen purge, prior to catalytic measurements. The products were analyzed by the on-line GC.

As shown in Figure S5, our catalytic tests show that $0.05 \mathrm{wt} \% \mathrm{Pt} / \mathrm{Al}_{2} \mathrm{O}_{3}$ catalyst is active for naphthalene hydrogenation. For example, at the reaction temperature of $130^{\circ} \mathrm{C}$, the naphthalene conversion is larger than $98 \%$. Under similar reaction conditions, naphthalene conversion over $0.05 \mathrm{wt} \% \mathrm{Pt} / \mathrm{ZSM}-5$ is less than $10 \%$. Furthermore, naphthalene conversion over $0.1 \mathrm{wt} \% \mathrm{Pt} / \mathrm{ZSM}-5$ is close to $30 \%$, whereas the conversion over $0.2 \mathrm{wt} \% \mathrm{Pt} / \mathrm{ZSM}-5$ and $0.5 \mathrm{wt} \% \mathrm{Pt} / \mathrm{ZSM}-5$ is similar to that of $0.05 \mathrm{wt} \% \mathrm{Pt} / \mathrm{Al}_{2} \mathrm{O}_{3}$ catalyst. On the other hand, as shown in Fig. 4c of main text, $0.05 \mathrm{wt} \% \mathrm{Pt} / \mathrm{ZSM}-5$ exhibits even higher catalytic activity than $0.05 \mathrm{wt} \% \mathrm{Pt} / \mathrm{Al}_{2} \mathrm{O}_{3}$ in acetylene hydrogenation. Thus, $0.05 \mathrm{wt} \% \mathrm{Pt} / \mathrm{ZSM}-5$ only show good activity towards acetylene hydrogenation but not for naphthalene hydrogenation. Indeed, due to the molecular sieving effect of ZSM-5, acetylene is accessible to Pt species located both within micropores and on the external surface of zeolite, while naphthalene is only accessible to Pt species located on the external surface of zeolite, but not encapsulated Pt nanoclusters. Therefore, the different catalytic activity of 0.05 wt \% Pt/ZSM-5 in acetylene hydrogenation and naphthalene hydrogenation clearly indicates that the majority of Pt presents as encapsulated nanoclusters in $0.05 \mathrm{wt} \% \mathrm{Pt} / \mathrm{ZSM}-5$ upon reduction, whereas for $0.1 \mathrm{wt} \% \mathrm{Pt} / \mathrm{ZSM}-5,0.2 \mathrm{wt} \% \mathrm{Pt} / \mathrm{ZSM}-5$, and $0.5 \mathrm{wt} \% \mathrm{Pt} / \mathrm{ZSM}-5$, part of Pt are located on the external surface of zeolite as nanoparticles upon reduction.

Figure S6 presents CO-DRIFT spectra of $0.05 \mathrm{wt} \% \mathrm{Pt} / \mathrm{ZSM}-5$ after ethane activation at $300{ }^{\circ} \mathrm{C}$ for 30 min, as well as $0.05 \mathrm{wt} \% \mathrm{Pt} / \mathrm{ZSM}-5$ after ethane activation followed by purge with $5 \% \mathrm{H}_{2}$ balanced in nitrogen at $300{ }^{\circ} \mathrm{C}$ for $2 \mathrm{~min}, 5 \mathrm{~min}, 10 \mathrm{~min}$, and $20 \mathrm{~min}$. These spectra clearly show that after purge at high temperature, the doublet feature decreases, while $\mathrm{CO}$ adsorption peak on nanoclusters increases. The correlation between increased intensity of the nanocluster peak and decreased intensity of the doublet feature, suggests that this double feature is related to the presence of Pt carbide. 
Figure S7 shows in-situ DRIFT spectra at DRIFTS mode of $0.05 \mathrm{wt} \% \mathrm{Pt} / \mathrm{ZSM}-5$ after reduction and $0.05 \mathrm{wt} \% \mathrm{Pt} / \mathrm{ZSM}-5$ after ethane activation. As expected, after reduction, there are no peaks in 1000 to 700 cm-1 range, whereas after ethane activation there appears two in-tense IR features in this range. As was discussed in the main text, these IR features observed on Pt/ZSM-5 after ethane activation are due to the presence of various $\mathrm{Pt}-\mathrm{C}$ stretching vibrations, further supporting the formation of $\mathrm{PtC}_{\mathrm{x}}$ species.

Figure S8 presents Raman spectra of $0.05 \mathrm{wt} \% \mathrm{Pt} / \mathrm{ZSM}-5$ after reduction, $0.05 \mathrm{wt} \% \mathrm{Pt} / \mathrm{ZSM}-5$ after ethane activation, and carbon coke supported on ZSM-5, in the range of 1100 to $2000 \mathrm{~cm}^{-1}$. Coke/ZSM-5 sample was prepared through ethane treatment of bare ZSM-5 at $700{ }^{\circ} \mathrm{C}$ for 1 hour. Raman spectrum of Pt/ZSM-5 after reduction does not show any noticeable Raman peaks. Raman spectrum of coke/ZSM-5 exhibits two typical Raman bands of carbon coke, D band and G band. Whereas, Raman spectrum of Pt/ZSM-5 after ethane activation exhibits several intense Raman bands. Such intense Raman bands are likely due to the formation of $\mathrm{PtC}_{\mathrm{x}}$ species, as discussed in the main text. Furthermore, Raman $\mathrm{D}$ band and G band peaks are absent in the spectrum of Pt/ZSM-5 after ethane activation. Therefore, the majority of carbon atoms in Pt/ZSM-5 after ethane activation are not in the form of coke or graphite, but are bound to Pt atoms.

Figure S9 shows CO-DRIFT spectra of $0.05 \mathrm{wt} \% \mathrm{Pt} / \mathrm{ZSM}-5$ after calcination, and $0.05 \mathrm{wt} \% \mathrm{Pt} / \mathrm{ZSM}-$ 5 after reduction, as well as used $0.05 \mathrm{wt} \% \mathrm{Pt} / \mathrm{ZSM}-5$ after regeneration and reduction. In the case of 0.05 wt $\%$ Pt/ZSM-5 after calcination, CO-DRIFTS measurements at $5{ }^{\circ} \mathrm{C}$ and $23{ }^{\circ} \mathrm{C}(\mathrm{RT})$ were both performed. For the measurement at $5{ }^{\circ} \mathrm{C}$, the whole reaction cell was cooled down to $5{ }^{\circ} \mathrm{C}$; $\mathrm{CO}$ adsorption $(10 \mathrm{~min})$, He purge $(5 \mathrm{~min})$, and DRIFTS measurements were all performed at this temperature. Whereas, for the measurement at RT, after $\mathrm{CO}$ adsorption at RT for $10 \mathrm{~min}$, the reaction cell was purged with $\mathrm{He}$ at RT for 30 min, prior to DRIFTS measurements at RT. CO-DRIFT spectrum performed at $5{ }^{\circ} \mathrm{C}$ for Pt/ZSM-5 after calcination clearly display two dominant features in the polycarbonyl region, suggesting the formation of isolated single Pt cations. ${ }^{18,56}$ Whereas, for the spectrum taken at RT, only one single CO peak centered at $2112 \mathrm{~cm}^{-1}$ is present. This agrees with the literature that upon long desorption at RT, Pt polycarbonyl peak 
intensity decreases, while a new single peak emerges and eventually becomes the only peak in the CODRIFT spectrum. ${ }^{18}$ Moreover, based on literatures, ${ }^{18,20}$ the position of this single peak again confirms the formation of isolated single Pt cations for Pt/ZSM-5 after calcination. On the other hand, as discussed in the main text, after reduction Pt forms small nanoclusters encapsulated in micropores of zeolite. CODRIFTS data in Figure S9 also show that for used Pt/ZSM-5 after regeneration and reduction, similar Pt nanoclusters are present, which is consistent with other characterization results, suggesting that forming Pt carbide does not cause the agglomeration or decomposition of nanoclusters.

As discussed above, for $0.05 \mathrm{wt} \% \mathrm{Pt} / \mathrm{ZSM}-5$ after calcination, $\mathrm{Pt}$ is in the presence of isolated single cations. Upon ethane treatments at $300{ }^{\circ} \mathrm{C}$ for $30 \mathrm{~min}$, the presence of Pt carbide over Pt/ZSM-5 after calcination was not identified, suggesting that the formation of Pt carbide is less favorable in the case of isolated single Pt atoms. In other words, reducing the nanocluster size to single dispersion does not promote the formation of Pt carbide. Similar conclusion has also been reported in the carburization process of Mo/ZSM-5 using methane or carbon monoxide..$^{24,27}$

Figure S10 displays CO-DRIFTS data of $0.05 \mathrm{wt} \%$ Pt/ZSM-5 after reduction, $0.05 \mathrm{wt} \% \mathrm{Pt} / \mathrm{ZSM}-5$ after ethane activation at $100{ }^{\circ} \mathrm{C}$ for $10 \mathrm{~min}, 0.05 \mathrm{wt} \% \mathrm{Pt} / \mathrm{ZSM}-5$ after ethane activation at $300{ }^{\circ} \mathrm{C}$ for 10 $\min , 0.05 \mathrm{wt} \% \mathrm{Pt} / \mathrm{ZSM}-5$ after ethane activation at $300{ }^{\circ} \mathrm{C}$ for $30 \mathrm{~min}, 0.05 \mathrm{wt} \% \mathrm{Pt} / \mathrm{ZSM}-5$ after ethane activation at $630{ }^{\circ} \mathrm{C}$ for $30 \mathrm{~min}, 0.05 \mathrm{wt} \% \mathrm{Pt} / \mathrm{ZSM}-5$ after ethane activation at $700{ }^{\circ} \mathrm{C}$ for $30 \mathrm{~min}$, and 0.05 $\mathrm{wt} \% \mathrm{Pt} / \mathrm{ZSM}-5$ after $\mathrm{CO}$ activation at $550{ }^{\circ} \mathrm{C}$ for $60 \mathrm{~min}$. These spectra clearly show that ethane activation at $100{ }^{\circ} \mathrm{C}$ does not promote the formation of $\mathrm{PtC}_{\mathrm{x}}$ species. Whereas, ethane activation at $300{ }^{\circ} \mathrm{C}$ for $10 \mathrm{~min}$ can transform part of Pt nanoclusters to Pt carbide nanoclusters, as evidenced by the co-existence of $\mathrm{CO}$ adsorption peak on Pt nanoclusters and the doublet feature related to $\mathrm{PtC}_{\mathrm{x}}$ nanoclusters. Furthermore, ethane activation at $300{ }^{\circ} \mathrm{C}$ for 30 min leads to the fully transformation of Pt nanoclusters to $\mathrm{PtC}_{\mathrm{x}}$ nanoclusters. Moreover, after ethane treatment at $630{ }^{\circ} \mathrm{C}$ for $30 \mathrm{~min}$, the double feature related to $\mathrm{PtC}_{\mathrm{x}}$ nanoclusters remains, while after ethane treatment at $700{ }^{\circ} \mathrm{C}$ for $30 \mathrm{~min}$, there is barely any adsorbed CO. Indeed, our TGA measurements show that there presents a large amount of carbon coke $(\sim 5 \%)$ after such treatment. 
Our catalytic measurements also show that after such treatment there is no catalytic activity in ethane aromatization and acetylene hydrogenation reactions. Thus, in the presence of ethane, $\mathrm{PtC}_{\mathrm{x}}$ species are stable at the temperature lower than $700{ }^{\circ} \mathrm{C}$, whereas, ethane treatment at $700{ }^{\circ} \mathrm{C}$ or higher mainly leads to the formation of carbon coke, which deactivate the catalysts.

Figure S1 1 shows CO-DRIFTS data of $0.05 \mathrm{wt} \% \mathrm{Pt} / \mathrm{ZSM}-5$ after reduction, $0.05 \mathrm{wt} \% \mathrm{Pt} / \mathrm{Al}_{2} \mathrm{O}_{3}$ after reduction, $0.2 \mathrm{wt} \% \mathrm{Pt} / \mathrm{ZSM}-5$ after reduction, $0.5 \mathrm{wt} \% \mathrm{Pt} / \mathrm{ZSM}-5$ after reduction, $0.5 \mathrm{wt} \% \mathrm{Pt} / \mathrm{ZSM}-5$ after ethane activation at $300{ }^{\circ} \mathrm{C}$ for $30 \mathrm{~min}$. For $0.05 \mathrm{wt} \% \mathrm{Pt} / \mathrm{ZSM}-5$ after reduction, there presents a single adsorption peak, which is assigned to CO adsorption on encapsulated Pt nanoclusters. Whereas, for $0.2 \mathrm{wt} \%$ Pt/ZSM-5 and 0.5 wt\% Pt/ZSM-5, there exists two CO adsorption peaks. One peak is at the same position as $0.05 \mathrm{wt} \% \mathrm{Pt} / \mathrm{ZSM}-5$, while the other peak is at the same position as $0.05 \mathrm{wt} \% \mathrm{Pt} / \mathrm{Al}_{2} \mathrm{O}_{3}$. Combination with the different performance in naphthalene hydrogenation as shown in Figure S5, we can assign these two peaks to $\mathrm{CO}$ adsorption on encapsulated Pt nanoclusters and on Pt nanoparticles supported on the external surface of zeolite, respectively. Apparently, for Pt/ZSM-5 with a higher Pt loading, Pt species are located both within micropores of zeolite and on the external surface of zeolite. Furthermore, Figure S11 also show that for Pt nanoparticles supported on the external surface of zeolite, ethane treatments at $300{ }^{\circ} \mathrm{C}$ do not lead to any significant changes, while the peak related to encapsulated Pt nanoclusters disappears, suggesting that the formation of Pt carbide is unfavorable for Pt nanoparticles supported on the external surface of zeolite, similar to Pt nanoparticles supported on $\mathrm{Al}_{2} \mathrm{O}_{3}$.

Figure $\mathrm{S} 12$ shows cluster geometries and calculated IR spectra for (a) $\mathrm{Pt}_{10} \mathrm{C}_{60}$ (core-shell), (b) $\mathrm{Pt}_{20} \mathrm{C}_{60}$ (core-shell), (c) $\mathrm{Pt}_{30} \mathrm{C}_{60}$ (core-shell), (d) $\mathrm{Pt}_{40} \mathrm{C}_{60}$ (core-shell), (e) $\mathrm{Pt}_{20} \mathrm{C}_{10}$ (ring), (f) $\mathrm{Pt}_{30} \mathrm{C}_{15}$ (ring), and (g) $\mathrm{Pt}_{40} \mathrm{C}_{20}$ (ring). $\mathrm{Pt}_{\mathrm{x}} \mathrm{C}_{60}$ (core-shell) cluster model, has the Pt cluster in the core enclosed by $\mathrm{C}_{60}$ as the shell. While, $\mathrm{Pt}_{\mathrm{x}} \mathrm{C}_{0.5 \mathrm{x}}$ (ring) cluster model has several carbon rings covering part of the Pt cluster. This model is built based on the assumption that only part of Pt cluster in the zeolite is exposed through the channel, and the $\mathrm{C}$ atoms can be accumulated on that part of Pt cluster. We optimized the geometries of these models and calculate their corresponding IR spectra, as well as the average $\mathrm{C}$ adsorption energies per $\mathrm{C}$ atom. 
The calculated average $\mathrm{C}$ adsorption energies per $\mathrm{C}$ atom for these cluster models, as well as regular $\mathrm{Pt}_{\mathrm{x}} \mathrm{C}_{0.5 \mathrm{x}}$ cluster models are listed in Table $\mathrm{S} 3$. The average $\mathrm{C}$ adsorption energies for the $\mathrm{Pt}_{\mathrm{x}} \mathrm{C}_{0.5 \mathrm{x}}$ (ring) and $\mathrm{Pt}_{\mathrm{x}} \mathrm{C}_{60}$ (core-shell) clusters are less negative than the regular $\mathrm{Pt}_{\mathrm{x}} \mathrm{C}_{0.5 \mathrm{x}}$ clusters. This suggests that regular $\mathrm{Pt}_{\mathrm{x}} \mathrm{C}_{0.5 \mathrm{x}}$ cluster models are thermodynamically more stable compared to the $\mathrm{Pt}_{\mathrm{x}} \mathrm{C}_{0.5 \mathrm{x}}$ (ring) and $\mathrm{Pt}_{\mathrm{x}} \mathrm{C}_{60}$ (coreshell) cluster models. In other words, the adsorption energy of $\mathrm{C}$ atoms on $\mathrm{Pt}_{\mathrm{x}}$ clusters is stronger than $\mathrm{C}$ atoms in small carbon rings or carbon clusters, and the formation of $\mathrm{PtC}_{\mathrm{x}}$ phase is more favorable than the formation of graphitic phase over $\mathrm{Pt}_{\mathrm{x}}$ clusters. In addition, the peaks of IR spectra of $\mathrm{Pt}_{\mathrm{x}} \mathrm{C}_{60}$ (core-shell) clusters are all located above $1100 \mathrm{~cm}^{-1}$, very different with experimental data. Thus, $\mathrm{Pt}_{\mathrm{x}} \mathrm{C}_{60}$ (core-shell) cluster models can be ruled out.

On the other hand, in the case of the $\mathrm{Pt}_{\mathrm{x}} \mathrm{C}_{0.5 \mathrm{x}}$ (ring) cluster models, the peaks of IR spectra are distributed much more broadly. Although $\mathrm{Pt}_{\mathrm{x}} \mathrm{C}_{0.5 \mathrm{x}}$ (ring) cluster models are thermodynamically less stable than regular $\mathrm{Pt}_{\mathrm{x}} \mathrm{C}_{0.5 \mathrm{x}}$ cluster model, the presence of such carbon rings on $\mathrm{Pt}_{\mathrm{x}} \mathrm{C}_{0.5 \mathrm{x}}$ clusters is very likely when $\mathrm{Pt} / \mathrm{ZSM}-5$ is treated with ethane, considering that ethane can be converted to BTX over $\mathrm{Pt}_{\mathrm{x}} \mathrm{C}_{0.5 \mathrm{x}}$ species. Therefore, experimental FTIR spectra in Figure S5 may also have some contributions from the presence of carbon rings on $\mathrm{Pt}_{\mathrm{x}} \mathrm{C}_{0.5 \mathrm{x}}$ clusters.

Figure S13 shows the structure models of possible adsorption sites for $\mathrm{C}$ atoms on/in $\mathrm{Pt}$ (111) surface/subsurface, as well as single Pt atoms anchored on the internal surface of ZSM-5. Figure S13a shows surface Top adsorption site of Pt (111). Figure S13b shows surface HCP adsorption site and subsurface HCP absorption site, while Figure S13c shows surface FCC adsorption site and subsurface FCC absorption site. As shown in Fig. 2b of main text, on Pt (111) surface, C adsorption over FCC site has lowest adsorption energy, followed by the HCP hollow site, while on top site it has highest adsorption energy of $-4.7 \mathrm{eV}$ (not shown here). In Pt (111) subsurface region, C absorption in subsurface HCP site is most favorable (has the same value as on surface HCP site), followed by slightly higher absorption energy in subsurface Top and FCC sites. Clearly, C adsorption on Pt (111) surface sites is more favorable than absorption in subsurface sites. 
Figure S13d shows optimized structures of one $\mathrm{C}$ atom adsorbed on single $\mathrm{Pt}$ atom anchored on the internal surface of ZSM-5. Our calculation shows that the $\mathrm{C}$ adsorption energy in this case is at $-6.73 \mathrm{eV}$, less favorable than $\mathrm{C}$ adsorption on Pt nanoclusters. We also examined adsorption of two $\mathrm{C}$ atoms on the ZSM-5 supported single Pt atom, Figure S13e. The average C adsorption energy for two C atoms is -6.14 $\mathrm{eV}$, less favorable compared to single $\mathrm{C}$ adsorption of $-6.73 \mathrm{eV}$, and much more unfavorable than $\mathrm{C}$ adsorption on Pt nanoclusters. This also suggests that single Pt atom may not function effectively for activating of molecules with multiple carbon atoms.

To further verify favorable adsorption sites of $\mathrm{C}$ atoms over Pt clusters, we tested additional scenarios beyond the ones shown in Fig. 2 of main text. We performed DFT geometry optimization, starting with manual insertion of a single carbon atom into subsurface region of $\mathrm{Pt}_{10}$ cluster. During geometry optimization, the carbon atom in subsurface sites would move out to the exterior of the $\mathrm{Pt}_{10}$ cluster, supporting the structures shown in Fig. 2 with carbon atoms mainly residing on the surface of clusters.

Figure S14 shows projected density of states (PDOS) for $\mathrm{Pt}_{\mathrm{x}} \mathrm{C}_{0.5 \mathrm{x}}$ and $\mathrm{Pt}_{\mathrm{x}}, \mathrm{X}=10,20,30,40$, and 50 . The horizontal black line, gray dashed line, and black dashed line indicate the Fermi level, the Pt d-band center of $\mathrm{Pt} \mathrm{x}_{\mathrm{x}}$ clusters, and the Pt d-band center of $\mathrm{Pt}_{\mathrm{x}} \mathrm{C}_{0.5 \mathrm{x}}$ clusters, respectively. The PAW potentials of Pt in the DFT calculations include $5 d$ electrons for valence states and $4 f$ electrons are kept in the core. The dband center is calculated as $\epsilon_{d}=\frac{\int \rho E d E}{\int \rho d E}$, where $\rho$ is the density of states and E is energy. From the PDOS plot in Figure S14, we find that the Pt $\mathrm{d}$ states shift to more negative energy from $\mathrm{Pt}_{\mathrm{x}}$ to $\mathrm{Pt}_{\mathrm{x}} \mathrm{C}_{0.5 \mathrm{x}}$ clusters, which is clearly shown by the positions of the d-band center indicated by dashed lines in the PDOS plots. These downshifting of $\mathrm{Pt} d$ states consistently appear in all $\mathrm{Pt}_{\mathrm{x}} \mathrm{C}_{0.5 \mathrm{x}}$ clusters investigated $(\mathrm{X}=10 \sim 50)$.

As the presence of $11545 \mathrm{eV}$ pre-edge peak in $\mathrm{Pt}_{3}$ XANES spectra of Pt carbide species is likely related to a change of electronic structure of Pt, along with the formation of Pt-C bonds, based on PDOS results, we tentatively attributed the presence of this pre-edge peak to the d-band shifting along with the formation of the $\mathrm{PtC}_{\mathrm{x}}$ structures. 
Figure $\mathrm{S} 15$ presents the calculated IR spectra of $\mathrm{Pt}_{2 \mathrm{x}} \mathrm{C}_{\mathrm{x}}(\mathrm{x}=5,10,15,20,25)$ clusters. It also contains a combined IR spectrum with equal contributions from each of the five individual IR spectra. The peaks in the combined spectrum were broadened by imposing a normal distribution with standard deviation of $5 \mathrm{~cm}^{-}$ 1. From our calculations of pure Pt clusters, the IR peaks all have wavenumbers less than $250 \mathrm{~cm}^{-1}$. The vibration modes in the range of $500-1000 \mathrm{~cm}^{-1}$ correspond to various vibrations of groups of $\mathrm{C}$ and $\mathrm{Pt}$ atoms. The calculated IR spectra show that there are several intense IR modes related to Pt-C bonds. The peak position of these modes, however, significantly varies with the value of $\mathrm{x}$. It is likely that our experimental DRIFTS data for Pt carbide nanoclusters have contributions from $\mathrm{Pt}_{2 \mathrm{x}} \mathrm{C}_{\mathrm{x}}$ clusters with different value of $x$. Indeed, as shown in Figure S15f, the combined spectrum with equal contribution differs noticeably with the individual spectrum, and it shows multiple peaks in a wide range, which is consistent with DRIFTS data shown in Figure S5. Therefore, our theoretical calculations are in line with experimental results.

Figure $\mathrm{S} 16$ shows the catalytic performance of $\mathrm{PtC}_{\mathrm{x}} / \mathrm{ZSM}-5$ catalyst in ethane aromatization at $630{ }^{\circ} \mathrm{C}$ and ambient pressure. $1 \mathrm{~g}$ of $0.05 \mathrm{wt} \% \mathrm{Pt} / \mathrm{ZSM}-5$ catalyst was loaded in a quartz reactor tube between two quartz wool plugs. Pt/ZSM-5 catalyst was first in-situ reduced with hydrogen at $630^{\circ} \mathrm{C}$ to form encapsulated Pt nanoclusters. After reduction, the hydrogen flow was switched to ethane flow and kept the reaction temperature at $630{ }^{\circ} \mathrm{C}$. After ethane activation for $10 \mathrm{~min}$, the effluent gas was analyzed by GC to obtain ethane conversion and product selectivities. Gas hourly space velocity (GHSV) of ethane is $1000 \mathrm{~h}^{-1}$. A small amount of nitrogen $(\sim 15 \%)$ was added to ethane flow, as the internal standard.

As shown in Figure $\mathrm{S} 16, \mathrm{PtC}_{\mathrm{x}} / \mathrm{ZSM}-5$ catalyst is highly active for ethane aromatization at $630{ }^{\circ} \mathrm{C}$, achieving $65 \%$ initial ethane conversion with $\sim 60 \%$ BTX selectivity. With the reaction going on, however, coke formation decreases the activity of the catalyst. Our experiments also show that the catalytic performance of $\mathrm{PtC}_{\mathrm{x}} / \mathrm{ZSM}-5$ catalyst can be recovered after oxidative regeneration of the deactivated catalyst at $550{ }^{\circ} \mathrm{C}$. Although similar activity has been reported on Pt/ZSM-5 catalyst using similar treatments, both active sites and chemical state of Pt under reaction conditions remain unknown. ${ }^{15}$ Our data 
show that under the ethane aromatization reaction, $\mathrm{Pt}$ is in the form of encapsulated $\mathrm{PtC}_{\mathrm{x}}$ nanoclusters, and such Pt carbide nanoclusters are the active phase in ethane aromatization.

The stability of $\mathrm{PtC}_{\mathrm{x}} / \mathrm{ZSM}-5$ catalyst under ethane aromatization and selective acetylene hydrogenation reactions has also been examined. Figure S17 shows in-situ UV-vis absorption spectra of Pt/ZSM-5 after reduction, and Pt/ZSM-5 after ethane activation, as well as Pt/ZSM-5 after ethane activation and following ethane aromatization reaction at $550^{\circ} \mathrm{C}$ for 2 hours, in other words used $\mathrm{PtC}_{\mathrm{x}} / \mathrm{ZSM}-5$. Clearly, used $\mathrm{PtC}_{\mathrm{x}} / \mathrm{ZSM}-5$ exhibits the same characteristic peak of Pt carbide nanoclusters in the UV-vis absorption spectra. Figure $\mathrm{S} 17$ thus indicates that $\mathrm{PtC}_{\mathrm{x}}$ species are relatively stable under ethane aromatization reaction conditions. Furthermore, after ethane aromatization reaction at $630{ }^{\circ} \mathrm{C}$ for $1 \mathrm{~h}$ to avoid the influence of carbon coke, $\mathrm{PtC}_{\mathrm{x}} / \mathrm{ZSM}-5$ catalyst was characterized with various techniques. These characterization measurements again show similar spectra as $\mathrm{Pt} / \mathrm{ZSM}-5$ after ethane activation, suggesting that $\mathrm{PtC}_{\mathrm{x}}$ nanomaterials are relatively stable under ethane aromatization reaction conditions.

Moreover, the performance of $\mathrm{PtC}_{\mathrm{x}} / \mathrm{ZSM}-5$ catalyst in the selective acetylene hydrogenation at $70{ }^{\circ} \mathrm{C}$ as a function of reaction time was shown in Figure S18. Cleary, there is no noticeable activity loss in the selective acetylene hydrogenation in the first two hours. The characterizations of the post-reaction sample also suggest that $\mathrm{Pt}$ carbide structure are preserved. This further confirms that $\mathrm{PtC}_{\mathrm{x}}$ nanomaterials are relatively stable under our catalytic reaction conditions.

The atomic ratio of Pt over $\mathrm{C}$ in formed Pt carbide was estimated based on the amount of $\mathrm{CO}_{2}$ generated through the oxygen treatment of $\mathrm{PtC}_{\mathrm{x}} / \mathrm{ZSM}-5$. In this experiment, a certain amount of $0.05 \mathrm{wt} \% \mathrm{Pt} / \mathrm{ZSM}-5$ was loaded in a quartz reactor tube between two quartz wool plugs. Pt/ZSM-5 sample was first in-situ reduced with hydrogen, followed by ethane activation at $300{ }^{\circ} \mathrm{C}$ for $30 \mathrm{~min}$, followed by nitrogen purge at RT for $2 \mathrm{~h}$. After that, 10\% oxygen balanced in nitrogen was flowed through the sample at RT, followed by the increase of temperature to $600{ }^{\circ} \mathrm{C}$ at $5{ }^{\circ} \mathrm{C} / \mathrm{min}$. The effluent gas was monitored online by the Hiden HPR-20 residual gas analyzer. The amount of $\mathrm{CO}_{2}$ generated was first subtracted by $\mathrm{CO}_{2}$ produced over 
bare ZSM-5 upon same ethane and oxygen treatments. Then the amount of $\mathrm{CO}_{2}$ resulting from Pt carbide was estimated by the comparison with the calibration curve. Furthermore, our data also indicate that the majority of $\mathrm{CO}_{2}$ was produced at the temperature below $200{ }^{\circ} \mathrm{C}$, whereas at similar temperature range, no signal of $\mathrm{CO}_{2}$ was observed in the coke burning procedure, suggesting that these $\mathrm{CO}_{2}$ generated are not from carbon coke. Based on the amount of $\mathrm{CO}_{2}$ generated and amount of Pt used, we roughly estimated that the atomic ratio of $\mathrm{Pt}$ over $\mathrm{C}$ in formed $\mathrm{Pt}$ carbide is at $\sim 2$. Similar ratio has also been obtained through the characterization with TGA.

Although only Pt carbide nanomaterials were prepared and examined in detail in this study, we also found that our approach can be extended to the synthesis of other metal carbides, for example manganese carbide. Mn/ZSM-5 sample was first prepared through the similar procedure as Pt/ZSM-5, involving steps of $\mathrm{Mn}$ impregnation, air calcination, and hydrogen reduction. After hydrogen reduction, Mn/ZSM-5 was then treated with ethane at $650{ }^{\circ} \mathrm{C}$ for $30 \mathrm{~min}$, followed by CO-DRIFTS measurements at RT. As shown in Figure S19, CO-DRIFT spectrum of Mn/ZSM-5 after ethane treatment shows several major peaks in two regions. Based on our knowledge on Pt/ZSM-5, we tentatively assign the peak at $2068 \mathrm{~cm}^{-1}$ to encapsulated Mn nanoclusters, and the peak at $2052 \mathrm{~cm}^{-1}$ to Mn nanoparticles supported on the external surface of zeolite. Both peaks are also present in the spectrum of Mn/ZSM-5 after reduction. Whereas, the peaks located at 2227, 2213, and $2196 \mathrm{~cm}^{-1}$ are not present in the spectrum of Mn/ZSM-5 after reduction, and are likely related to the presence of $\mathrm{Mn}$ carbide nanoclusters. Our data thus suggest that Mn carbide nanomaterials can also be prepared under mild conditions through supported Mn nanoclusters.

In conclusion, our work provides a new universal approach to prepare metal carbide-based catalytic materials under mild conditions. Considering that that many transition metal carbides have been synthesized under high pressure and high temperature conditions, including rhenium carbide, ${ }^{57}$ tantalum carbide, ${ }^{58}$ manganese carbide, ${ }^{59}$ iridium carbide, ${ }^{60}$ and osmium carbide, ${ }^{61}$ as well as interesting catalytic behaviors of many metal carbides, our finding may open up new directions in the catalytic study of metal carbide-based nanomaterials. 
35. Kresse, G.; Hafner, J. Ab initio molecular dynamics for liquid metals. Phys. Rev. B. 1992, 47, 558561.

36. Kresse, G.; Furthmuller, J. Efficiency of ab-initio total energy calculations for metals and semiconductors using a plane-wave basis set. Comput. Mater. Sci. 1996, 6, 15-50.

37. Blöchl, P. E. Projector augmented-wave method. Phys. Rev. B. 1994, 50, 17953-17979.

38. Perdew, J. P.; Burke, K.; Ernzerhof, M. Generalized Gradient Approximation Made Simple. Phys. Rev. Lett. 1996, 77, 3865-3868.

39. Jacobsen, K. W.; Stoltze, P.; Nørskov, J. K. A semi-empirical effective medium theory for metals and alloys. Surf. Sci. 1996, 366, 394-402.

40. Vilhelmsen, L. B.; Hammer, B. Systematic Study of Au6to Au12Gold Clusters on MgO(100) FCenters Using Density-Functional Theory. Phys. Rev. Lett. 2012, 108, 126101.

41. Vilhelmsen, L. B.; Hammer, B. A genetic algorithm for first principles global structure optimization of supported nano structures. J. Chem. Phys. 2014, 141, 044711.

42. Larsen, A. H.; Mortensen, J. J.; Blomqvist, J.; Castelli, I. E.; Christensen, R.; Dułak, M.; Friis, J.; Groves, M. N.; Hammer, B.; Hargus, C.; Hermes, E. D.; Jennings, P. C.; Jensen, P. B.; Kermode, J.; Kitchin, J. R.; Kolsbjerg, E. L.; Kubal, J.; Kaasbjerg, K.; Lysgaard, S.; Maronsson, J. B.; Maxson, T.; Olsen, T.; Pastewka, L.; Peterson, A.; Rostgaard, C.; Schiøtz, J.; Schütt, O.; Strange, M.; Thygesen, K. S.; Vegge, T.; Vilhelmsen, L.; Walter, M.; Zeng, Z.; Jacobsen, K. W. The atomic simulation environment-a Python library for working with atoms. J. Phys. Condens. Matter 2017, 29, 273002.

43. Grimme, S. Semiempirical GGA - type density functional constructed with a long - range dispersion correction. J. Comput. Chem. 2006, 27, 1787-1799.

44. Ismagilov, Z. R.; Matus, E. V.; Tsikoza, L. T. Direct conversion of methane on Mo/ZSM-5 catalysts to produce benzene and hydrogen: achievements and perspectives. Energy Environ. Sci. 2008, 1, 526-541.

45. Olson, D. H.; Kokotailo, G. T.; Lawton, S. L.; Meier, W. M. Crystal structure and structure-related properties of ZSM-5. J. Phys. Chem. A 1981, 85, 2238-2243.

46. Giannozzi, P.; Baroni, S. Vibrational and dielectric properties of C60 from density - functional perturbation theory. J. Chem. Phys. 1994, 100, 8537-8539.

47. Esfarjani, K.; Hashi, Y.; Onoe, J.; Takeuchi, K.; Kawazoe, Y. Vibrational modes and IR analysis of neutral photopolymerized C 60 dimers. Phys. Rev. B 1998, 57, 223.

48. Baroni, S.; De Gironcoli, S.; Dal Corso, A.; Giannozzi, P. Phonons and related crystal properties from density-functional perturbation theory. Rev. Mod. Phys. 2001, 73, 515.

49. Karhánek, D.; Bučko, T.; Hafner, J. A density functional study of the adsorption of methane-thiol on the (111) surfaces of the Ni-group metals: I. Molecular and dissociative adsorption. J. Phys. Condens. Matter 2010, 22, 265005.

50. Karhánek, D.; Bučko, T.; Hafner, J. A density-functional study of the adsorption of methane-thiol on the (111) surfaces of the Ni-group metals: II. Vibrational spectroscopy. J. Phys. Condens. Matter 2010, 22, 265006 . 
51. Goel, S.; Wu, Z.; Zones, S. I.; Iglesia, E. Synthesis and Catalytic Properties of Metal Clusters Encapsulated within Small-Pore (SOD, GIS, ANA) Zeolites. J. Am. Chem. Soc. 2012, 134, 17688-17695.

52. Zhai, Y.; Pierre, D.; Si, R.; Deng, W.; Ferrin, P.; Nilekar, A. U.; Peng, G.; Herron, J. A.; Bell, D. C.; Saltsburg, H.; Mavrikakis, M.; Flytzani-Stephanopoulos, M. Alkali-Stabilized Pt-OHx Species Catalyze Low-Temperature Water-Gas Shift Reactions. Science 2010, 329, 1633-1636.

53. Itoi, H.; Nishihara, H.; Kobayashi, S.; Ittisanronnachai, S.; Ishii, T.; Berenguer, R.; Ito, M.; Matsumura, D.; Kyotani, T. Fine Dispersion of Pt4-5 Subnanoclusters and Pt Single Atoms over Porous Carbon Supports and Their Structural Analyses with X-ray Absorption Spectroscopy. J. Phys. Chem. C 2017, 121, 7892-7902.

54. Jung, U.; Elsen, A.; Li, Y.; Smith, J. G.; Small, M. W.; Stach, E. A.; Frenkel, A. I.; Nuzzo, R. G. Comparative in Operando Studies in Heterogeneous Catalysis: Atomic and Electronic Structural Features in the Hydrogenation of Ethylene over Supported Pd and Pt Catalysts. ACS Catal. 2015, 5, 1539-1551.

55. de Graaf, J.; van Dillen, A. J.; de Jong, K. P.; Koningsberger, D. C. Preparation of Highly Dispersed Pt Particles in Zeolite Y with a Narrow Particle Size Distribution: Characterization by Hydrogen Chemisorption, TEM, EXAFS Spectroscopy, and Particle Modeling. J. Catal. 2001, 203, 307-321.

56. Xu, Q. Metal carbonyl cations: generation, characterization and catalytic application. Coord. Chem. Rev. 2002, 231, 83-108.

57 Yasui, N.; Sougawa, M.; Hirai, M.; Yamamoto, K.; Okada, T.; Yamazaki, D.; Kojima, Y.; Ohfuji, H.; Kunitsugu, S.; Takarabe, K. High-pressure and high-temperature synthesis of rhenium carbide using rhenium and nanoscale amorphous two-dimensional carbon nitride. Cogent Phys. 2015, 2, 1076702.

58 Preiss, H.; Schultze, D.; Klobes, P. Formation of $\mathrm{NbC}$ and TaC from gel-derived precursors. J. Eur. Ceram. Soc. 1997, 17, 1423-1435.

59 Arpita Aparajita, A. N.; Sanjay Kumar, N. R.; Chandra, S.; Amirthapandian, S.; Shekar, N. V. C.; Sridhar, K. High-Pressure Synthesis of Manganese Monocarbide: A Potential Superhard Material. Inorg. Chem. 2018, 57, 14178-14185.

60 Sanjay Kumar, N. R.; Aparajita Arpita, A. N.; Chandra Shekar, N. V. High pressure synthesis of iridium carbide. Bhabha Atomic Research Centre: India, 2016.

61 Kumar, N. R. S.; Chandra, S.; Amirthapandian, S.; Chandra Shekar, N. V.; Ch Sahu, P. Investigations of the high pressure synthesized osmium carbide by experimental and computational techniques. Mater. Res. Express 2015, 2, 016503. 
Table S1. Pt dispersion and particle size of various samples, estimated from CO dynamic chemisorption data in Figure S2a.

\begin{tabular}{|c|c|c|}
\hline Samples & Pt dispersion & Particle size \\
\hline $\begin{array}{c}\text { Used Pt/ZSM-5 after } \\
\text { regeneration and reduction }\end{array}$ & $\sim 100 \%$ & $\sim 1 \mathrm{~nm}$ or $<1 \mathrm{~nm}$ \\
\hline $\mathbf{P t} / \mathbf{Z S M}-5$ after reduction & $\sim 100 \%$ & $\sim 1 \mathrm{~nm} \mathrm{or}<1 \mathrm{~nm}$ \\
\hline $\mathbf{P t} / \mathbf{A l}_{2} \mathbf{O}_{3}$ after reduction & $21 \%$ & $6 \mathrm{~nm}$ \\
\hline Bare $\mathbf{Z S M}-5$ after reduction & N/A & N/A \\
\hline
\end{tabular}


Table S2. Quantitative analyses for $\mathrm{Pt}_{1}-\mathrm{O}$ ( $\mathrm{Pt}-\mathrm{O}$ bond of isolated single $\mathrm{Pt}$ atoms), $\mathrm{Pt}_{\mathrm{n}}-\mathrm{O}$ ( $\mathrm{Pt}-\mathrm{O}$ bond of $\mathrm{Pt}$ nanoclusters with framework O atoms), and Pt-Pt contributions from the EXAFS data in Figure S4.

\begin{tabular}{|c|c|c|c|c|}
\hline Samples & Shell & $\mathrm{CN}^{(\mathbf{a})}$ & $R(A)^{(b)}$ & $\sigma^{2}\left(\AA^{2}\right)$ \\
\hline \multirow{3}{*}{$\begin{array}{c}0.05 \text { wt } \% \text { Pt } / \mathrm{ZSM}-5 \text { after } \\
\text { calcination }\end{array}$} & $\mathrm{Pt}_{1}-\mathrm{O}$ & $4.0 \pm 0.6$ & $1.98 \pm 0.02$ & 0.002 \\
\hline & $\mathrm{Pt}_{\mathrm{n}}-\mathrm{O}$ & 0 & & \\
\hline & Pt-Pt & 0 & & \\
\hline \multirow{3}{*}{$\begin{array}{c}0.05 \mathrm{wt} \% \mathrm{Pt} / \mathrm{ZSM}-5 \text { after } \\
\text { reduction }\end{array}$} & $\mathrm{Pt}_{1}-\mathrm{O}$ & $0.4 \pm 0.2$ & $2.05 \pm 0.04$ & 0.004 \\
\hline & $\mathrm{Pt}_{\mathrm{n}}-\mathrm{O}$ & $1.2 \pm 0.4$ & $2.57 \pm 0.05$ & 0.011 \\
\hline & $\mathrm{Pt}-\mathrm{Pt}$ & $5.4 \pm 0.8$ & $2.76 \pm 0.03$ & 0.007 \\
\hline \multirow{3}{*}{$\begin{array}{c}0.05 \mathrm{wt} \% \mathrm{Pt} / \mathrm{ZSM}-5 \text { after } \\
\text { ethane activation }\end{array}$} & $\mathrm{Pt}_{1}-\mathrm{O}$ & $0.3 \pm 0.2$ & $2.08 \pm 0.05$ & 0.002 \\
\hline & $\mathrm{Pt}_{\mathrm{n}}-\mathrm{O}$ & $1.9 \pm 0.5$ & $2.55 \pm 0.06$ & 0.009 \\
\hline & $\mathrm{Pt}-\mathrm{Pt}$ & $5.9 \pm 0.9$ & $2.74 \pm 0.04$ & 0.003 \\
\hline
\end{tabular}

[a] CN, coordination number; [b] R, distance between absorber and backscattered atoms. 
Table S3. Calculated average $\mathrm{C}$ adsorption energy per $\mathrm{C}$ atom for cluster models of $\mathrm{Pt}_{\mathrm{x}} \mathrm{C}_{0.5 \mathrm{x}}, \mathrm{Pt}_{\mathrm{x}} \mathrm{C}_{0.5 \mathrm{x}}(\mathrm{ring})$, and $\mathrm{Pt}_{\mathrm{x}} \mathrm{C}_{60}$ (core-shell).

\begin{tabular}{|c|c|c|c|c|}
\hline \multirow{2}{*}{} & \multicolumn{4}{|c|}{ Number of Pt atoms $(\mathrm{X})$} \\
\cline { 2 - 5 } & 10 & 20 & 30 & 40 \\
\hline $\mathrm{Pt}_{\mathrm{x}} \mathrm{C}_{0.5 \mathrm{x}}$ & -7.56 & -7.22 & -7.21 & -7.18 \\
\hline $\mathrm{Pt}_{\mathrm{x}} \mathrm{C}_{0.5 \mathrm{x}}($ ring) & - & -7.02 & -7.04 & -7.06 \\
\hline $\mathrm{Pt}_{\mathrm{x}} \mathrm{C}_{60}$ (core-shell) & -7.46 & -7.02 & -6.82 & -6.79 \\
\hline
\end{tabular}



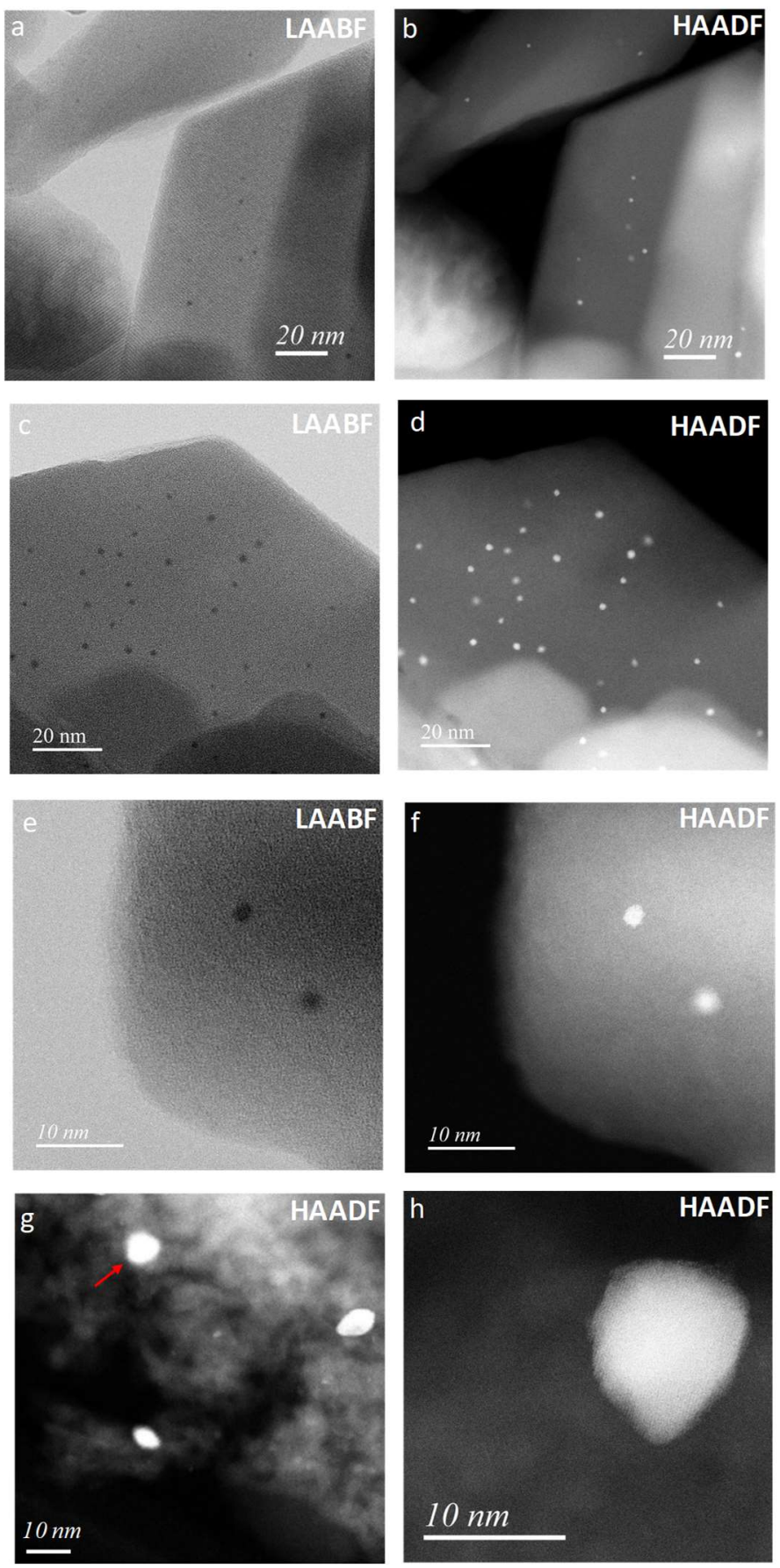

Figure S1. STEM images of various supported Pt samples. a, LAABF-STEM image of $0.05 \mathrm{wt} \% \mathrm{Pt} / \mathrm{ZSM}-5$ after reduction; b, HAADF-STEM image of 0.05 wt $\%$ Pt/ZSM-5 after reduction. c, LAABF-STEM image of $0.05 \mathrm{wt} \%$ Pt/ZSM-5 after ethane activation; d, HAADF-STEM image of $0.05 \mathrm{wt} \%$ Pt/ZSM-5 after ethane activation. e, LAABFSTEM image of used $0.05 \mathrm{wt} \% \mathrm{Pt} / \mathrm{ZSM}-5$ after regeneration and reduction; f, HAADF-STEM image of $0.05 \mathrm{wt} \%$ Pt/ZSM-5 after regeneration and reduction. $\mathbf{g}$ and $\mathbf{h}, \mathrm{HAADF}-\mathrm{STEM}$ images of $0.05 \mathrm{wt} \% \mathrm{Pt} / \mathrm{Al}_{2} \mathrm{O}_{3}$ after reduction. 

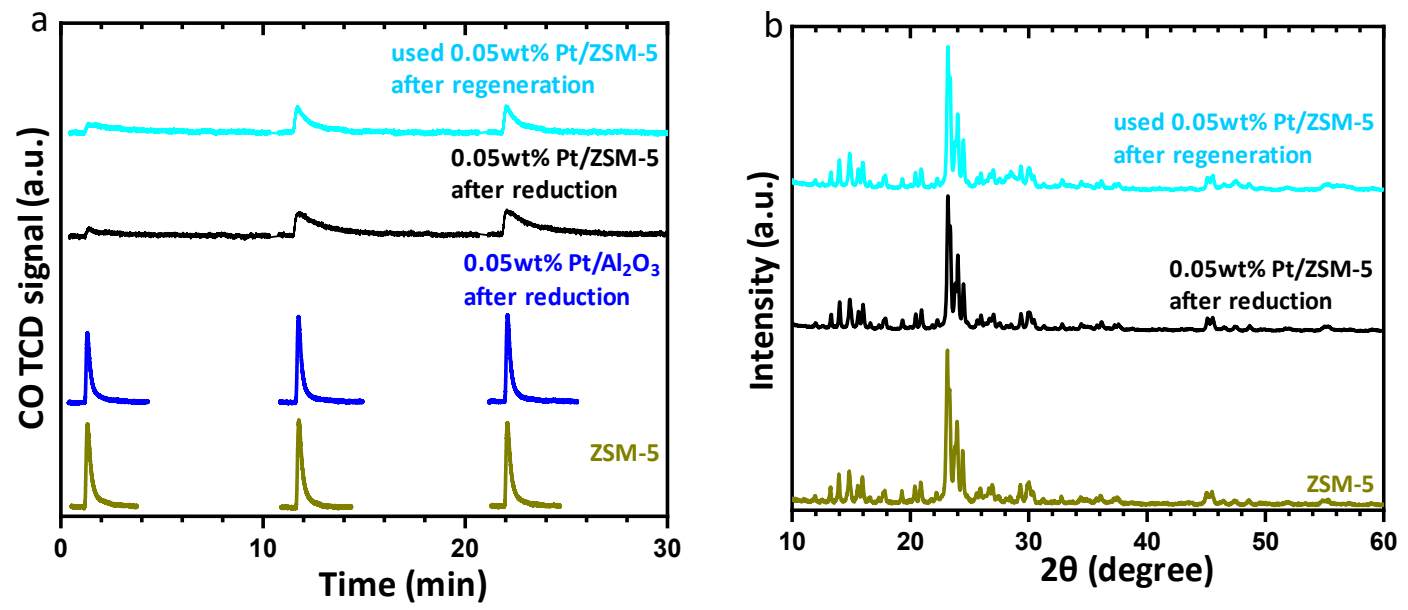

Figure S2. CO dynamic chemisorption and XRD of Pt/ZSM-5 and $\mathrm{Pt} / \mathrm{Al}_{2} \mathrm{O}_{3}$ after various treatments. a, $\mathrm{CO}$ dynamic chemisorption of bare ZSM-5, $0.05 \mathrm{wt} \% \mathrm{Pt} / \mathrm{Al}_{2} \mathrm{O}_{3}$ after reduction, and $0.05 \mathrm{wt} \% \mathrm{Pt} / \mathrm{ZSM}-5$ after reduction. Pt dispersion and particle size of various samples estimated from CO dynamic chemisorption are listed in Table S1. b, XRD pattern of bare ZSM-5, $0.05 \mathrm{wt} \% \mathrm{Pt} / \mathrm{ZSM}-5$ after reduction, and used $0.05 \mathrm{wt} \% \mathrm{Pt} / \mathrm{ZSM}-5$ after regeneration. 


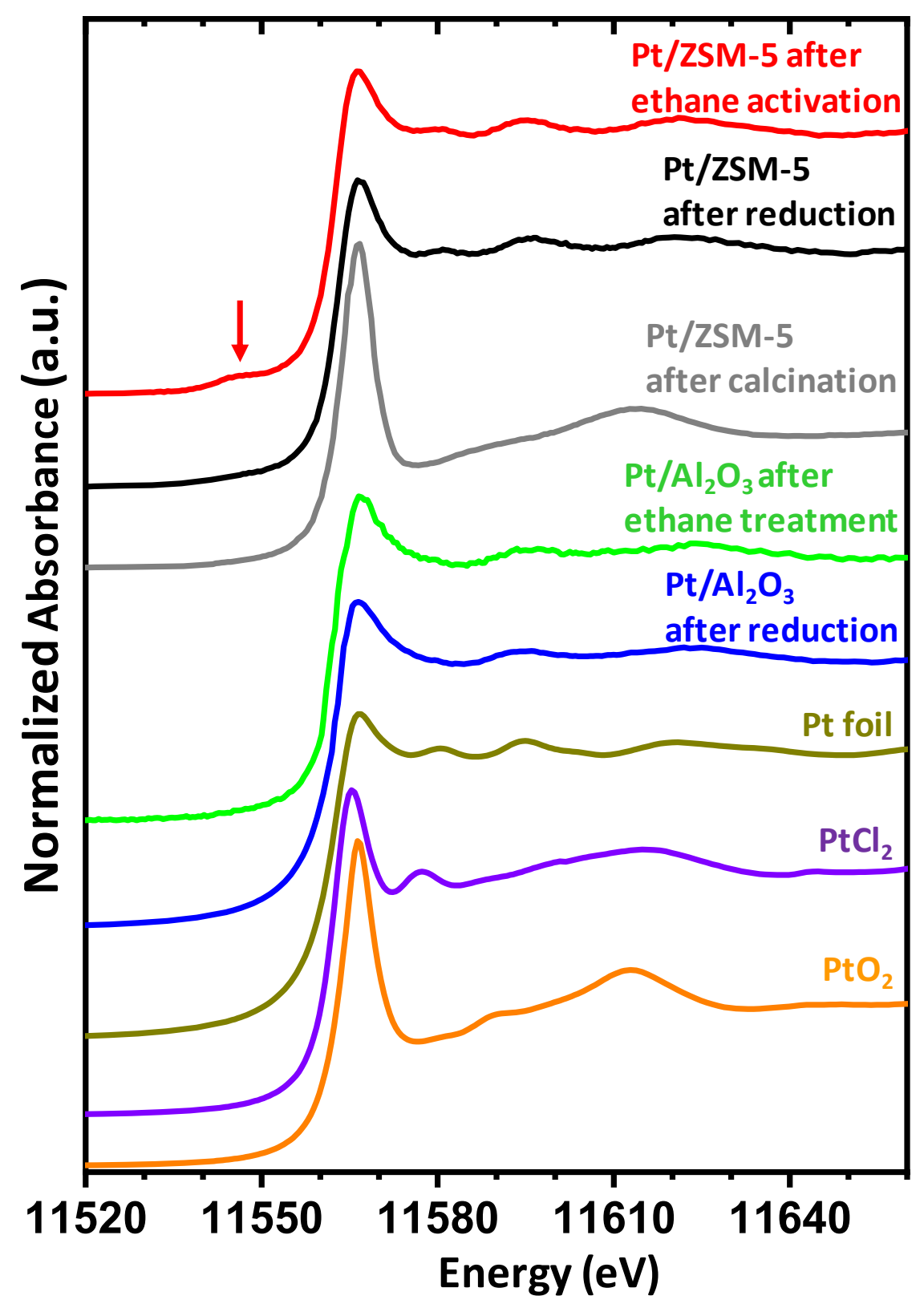

Figure S3. Normalized Pt $\mathrm{L}_{3}$-edge XANES spectra of $0.05 \mathrm{wt} \% \mathrm{Pt} / \mathrm{ZSM}-5$ after calcination, $0.05 \mathrm{wt} \% \mathrm{Pt} / \mathrm{ZSM}-5$ after reduction, $0.05 \mathrm{wt} \% \mathrm{Pt} / \mathrm{ZSM}-5$ after ethane activation, $0.05 \mathrm{wt} \% \mathrm{Pt} / \mathrm{Al}_{2} \mathrm{O}_{3}$ after reduction, and $0.05 \mathrm{wt} \% \mathrm{Pt} / \mathrm{Al}_{2} \mathrm{O}_{3}$ after ethane treatment, as well as $\mathrm{Pt}$ foil, $\mathrm{PtO}_{2}$, and $\mathrm{PtCl}_{2}$ standards. All Pt/ZSM-5 and $\mathrm{Pt} / \mathrm{Al}_{2} \mathrm{O}_{3}$ data were collected in fluorescence mode at RT. Approximately 10 consecutive scans were collected for each sample to improve the signalto-noise ratio. All Pt standards were collected at transmission mode at RT. 


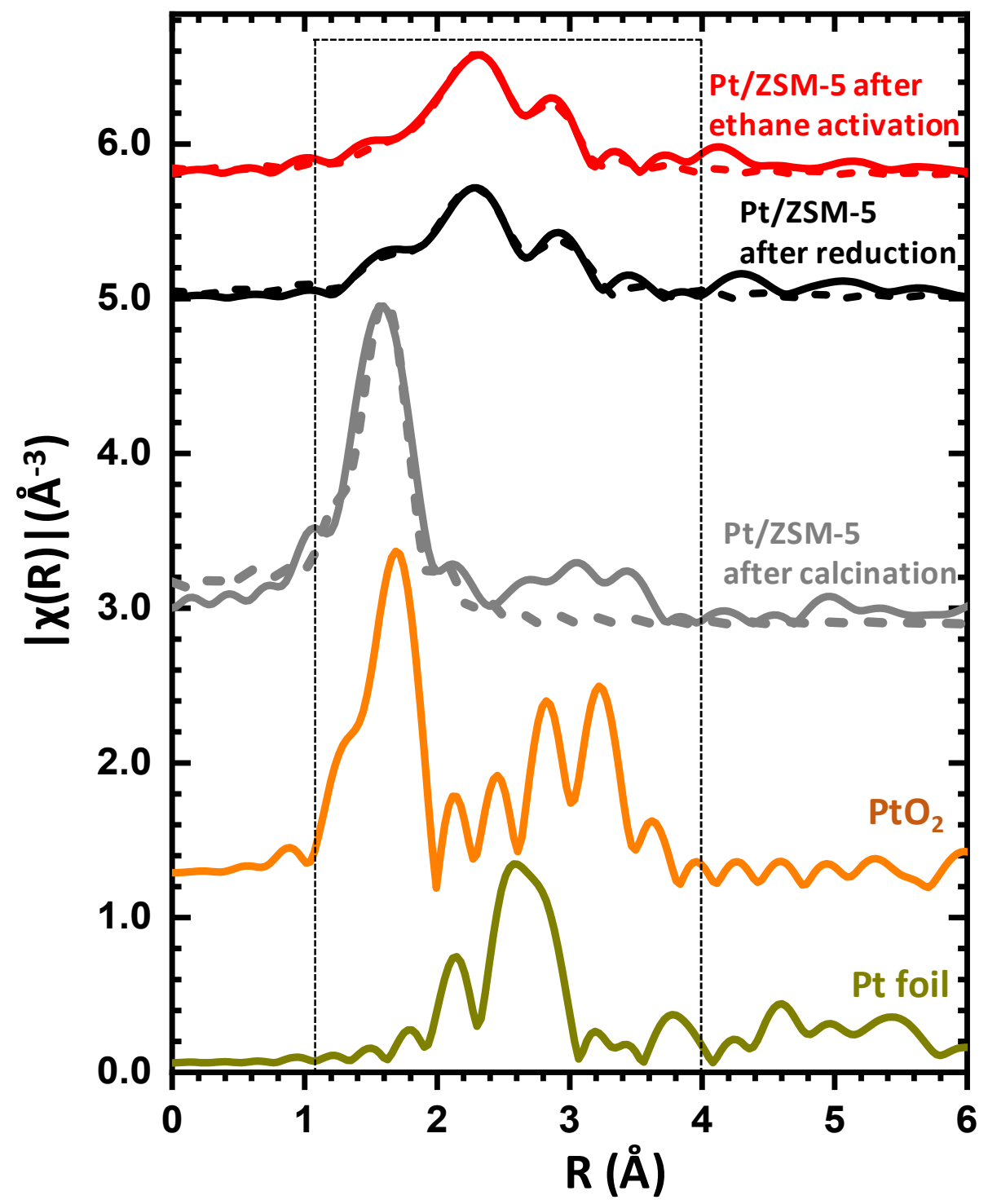

Figure S4. Pt $\mathrm{L}_{3}$-edge EXAFS spectra of $0.05 \mathrm{wt} \% \mathrm{Pt} / \mathrm{ZSM}-5$ after calcination, $0.05 \mathrm{wt} \% \mathrm{Pt} / \mathrm{ZSM}-5$ after reduction, $0.05 \mathrm{wt} \% \mathrm{Pt} / \mathrm{ZSM}-5$ after ethane activation, $\mathrm{PtO}_{2}$ standard, and $\mathrm{Pt}$ foil standard. The dotted lines are the fitting of three samples. The Quantitative analyses for these EXAFS data are shown in Table S2. All Pt/ZSM-5 data were collected in fluorescence mode at RT. Approximately 10 consecutive scans were collected for each sample to improve the signal-to-noise ratio. All Pt standards were collected at transmission mode at RT. 


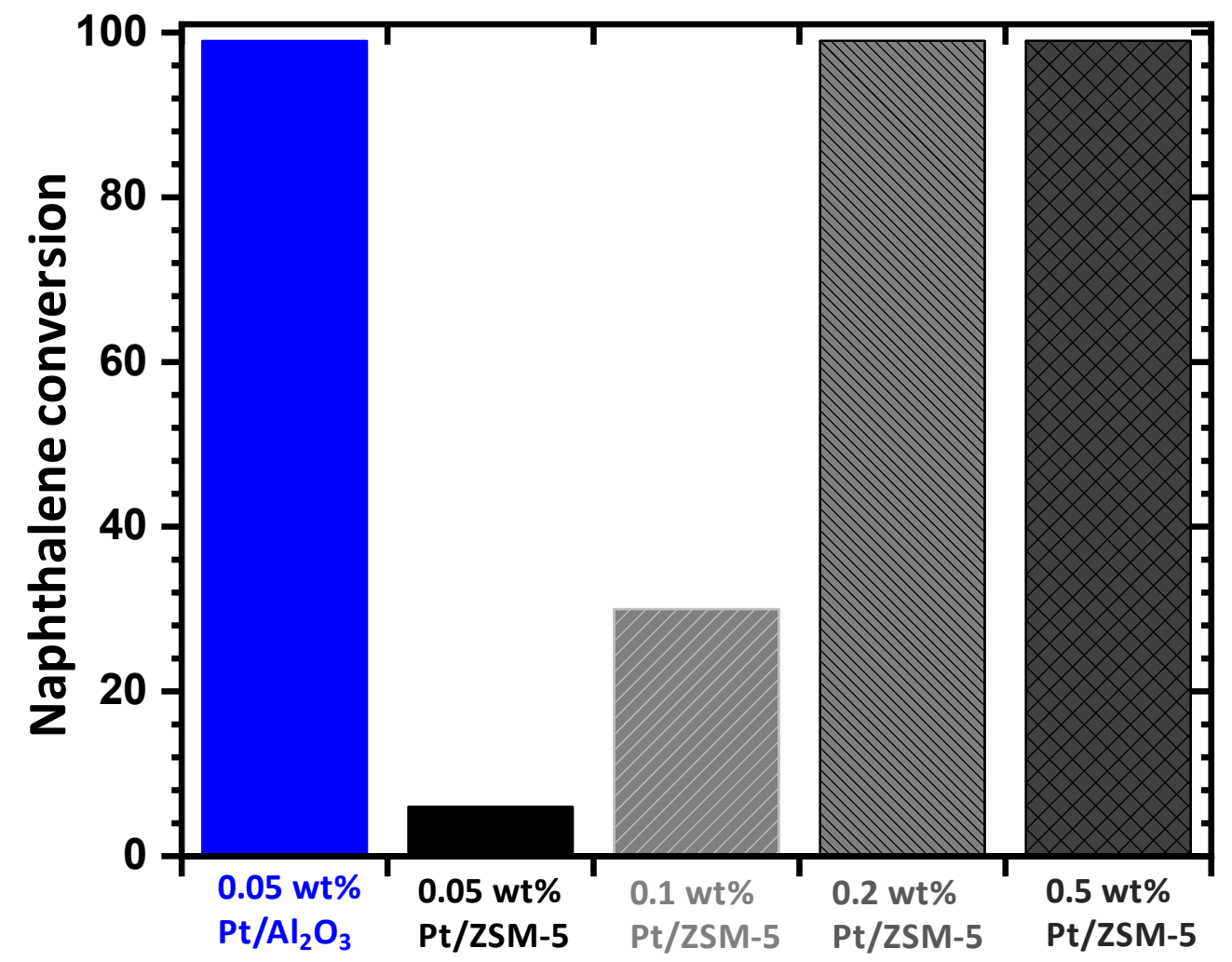

Figure S5. Catalytic activity of $0.05 \mathrm{wt} \% \mathrm{Pt} / \mathrm{Al}_{2} \mathrm{O}_{3}$ after reduction, $0.05 \mathrm{wt} \% \mathrm{Pt} / \mathrm{ZSM}-5$ after reduction, $0.1 \mathrm{wt} \%$ $\mathrm{Pt} / \mathrm{ZSM}-5$ after reduction, $0.2 \mathrm{wt} \% \mathrm{Pt} / \mathrm{ZSM}-5$ after reduction, and $0.5 \mathrm{wt} \% \mathrm{Pt} / \mathrm{ZSM}-5$ after reduction in the naphthalene hydrogenation reaction. 


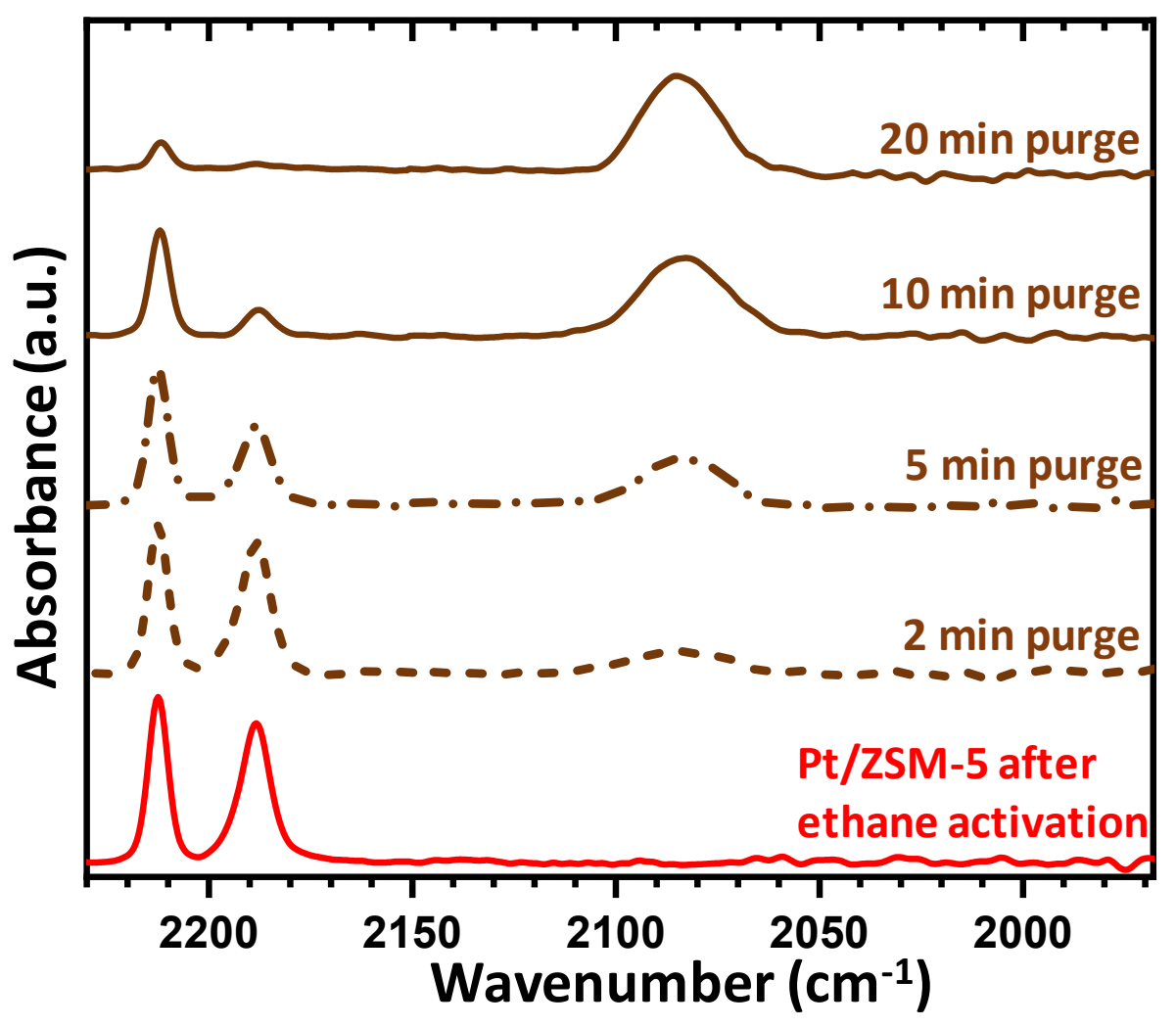

Figure S6. In-situ CO-DRIFT spectra of $0.05 \mathrm{wt} \% \mathrm{Pt} / \mathrm{ZSM}-5$ after ethane activation at $300{ }^{\circ} \mathrm{C}$ for $30 \mathrm{~min}, 0.05 \mathrm{wt} \%$ Pt/ZSM-5 after ethane activation followed by purge with $5 \% \mathrm{H}_{2}$ balanced in nitrogen at $300{ }^{\circ} \mathrm{C}$ for $2 \mathrm{~min}, 5 \mathrm{~min}, 10$ min, and $20 \mathrm{~min}$, respectively. 


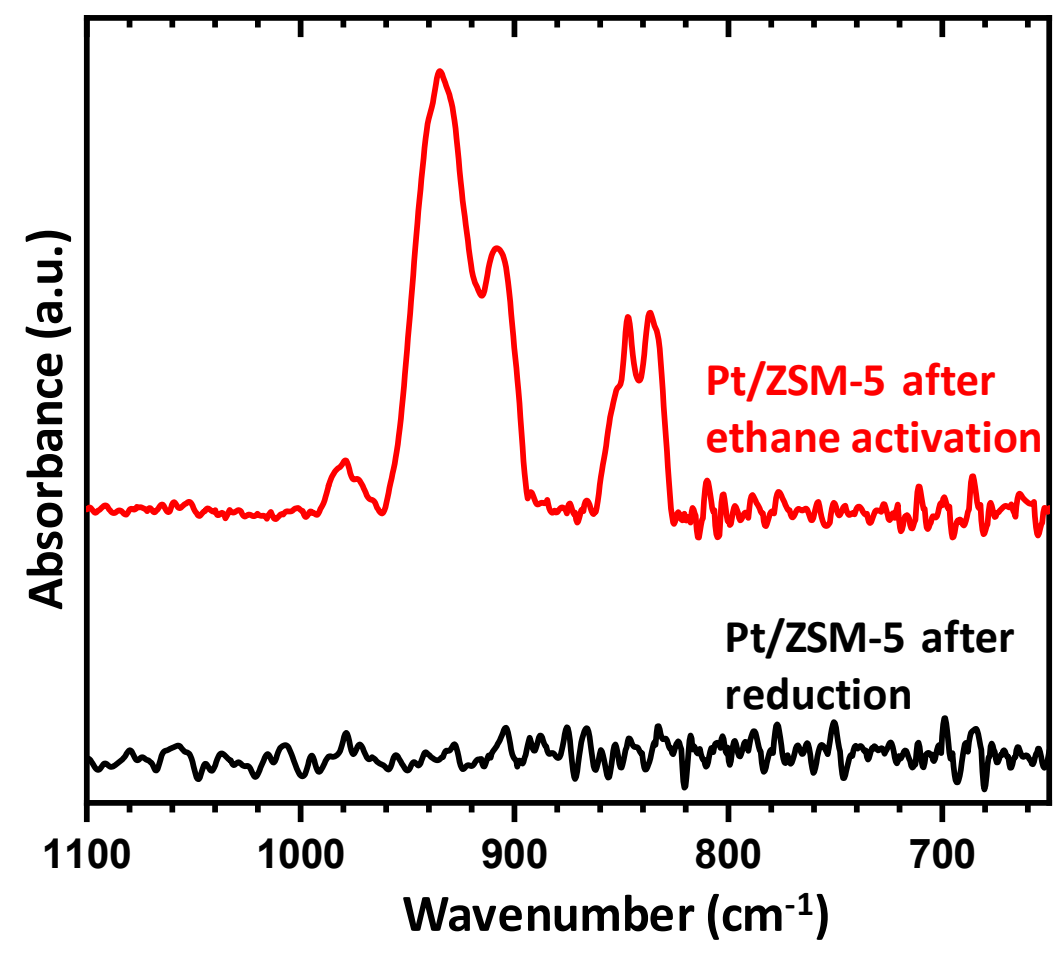

Figure S7. In-situ DRIFT spectra of $0.05 \mathrm{wt} \% \mathrm{Pt} / \mathrm{ZSM}-5$ after reduction and $0.05 \mathrm{wt} \% \mathrm{Pt} / \mathrm{ZSM}-5$ after ethane activation. 


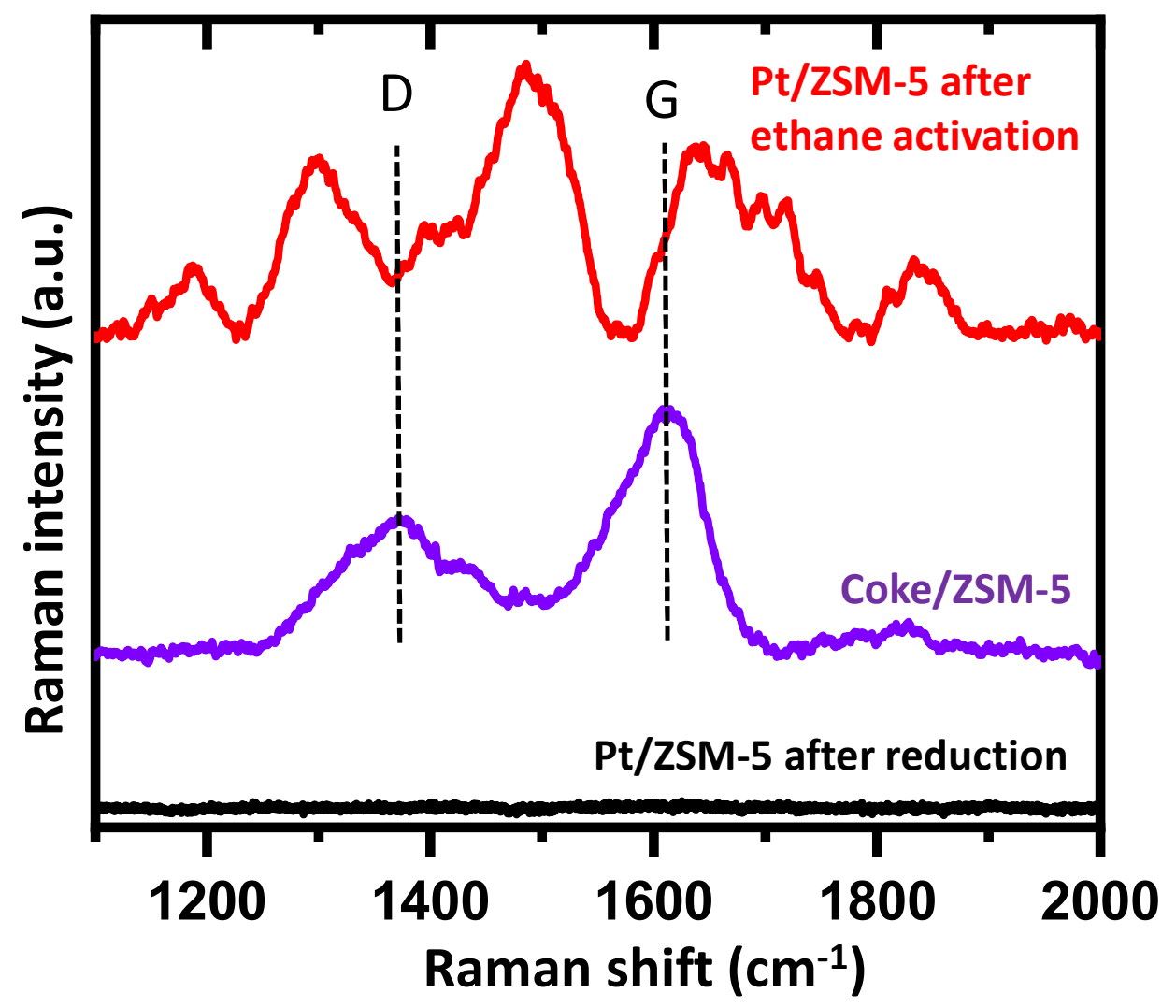

Figure S8. Raman spectra of Pt/ZSM-5 after reduction, Pt/ZSM-5 after ethane activation, and carbon coke on ZSM5. 


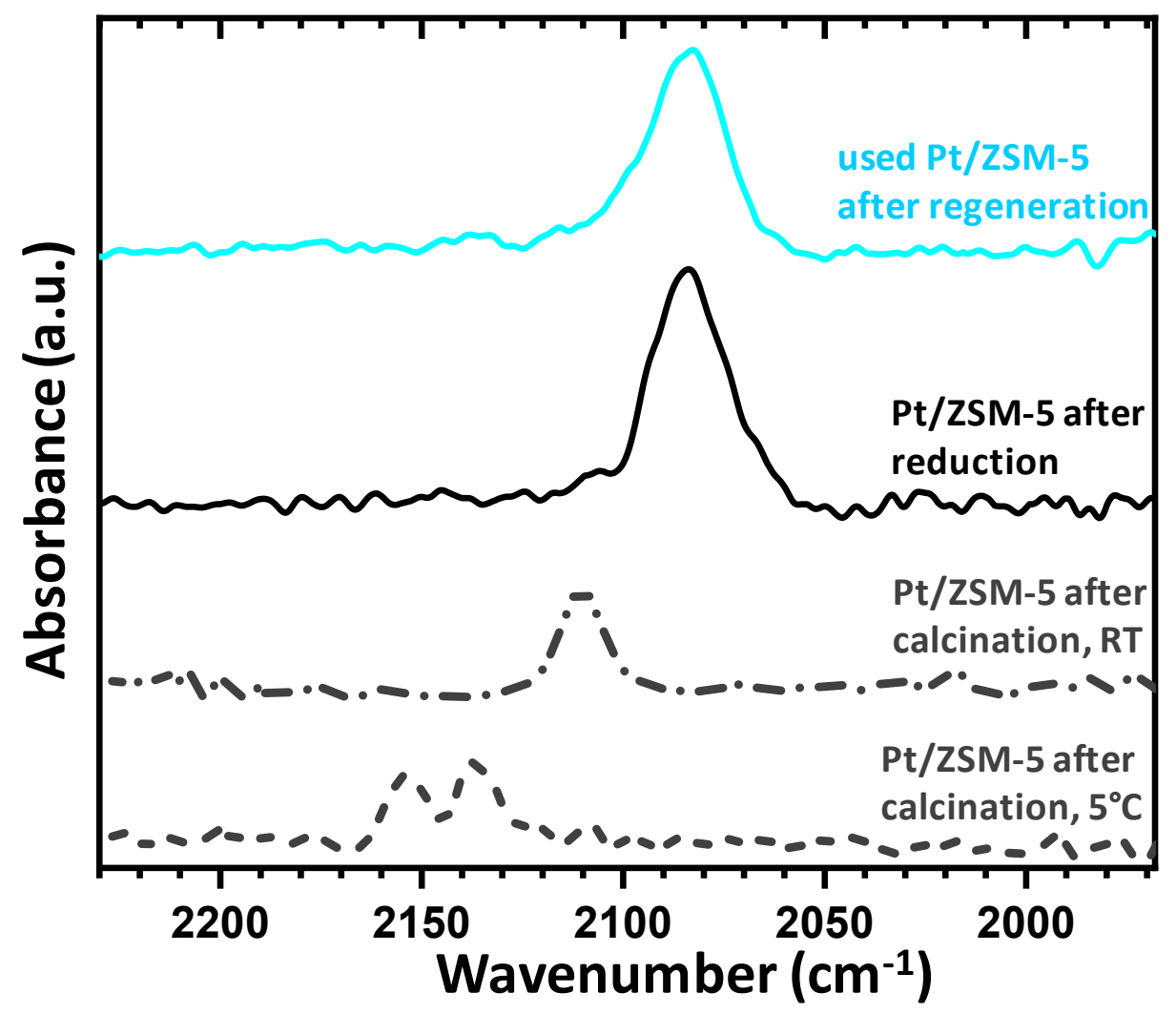

Figure S9. In-situ CO-DRIFT spectra of $0.05 \mathrm{wt} \% \mathrm{Pt} / \mathrm{ZSM}-5$ after calcination $\left(5{ }^{\circ} \mathrm{C}\right), 0.05 \mathrm{wt} \% \mathrm{Pt} / \mathrm{ZSM}-5$ after calcination (RT), $0.05 \mathrm{wt} \% \mathrm{Pt} / \mathrm{ZSM}-5$ after reduction, and used $0.05 \mathrm{wt} \% \mathrm{Pt} / \mathrm{ZSM}-5$ after regeneration and reduction. 


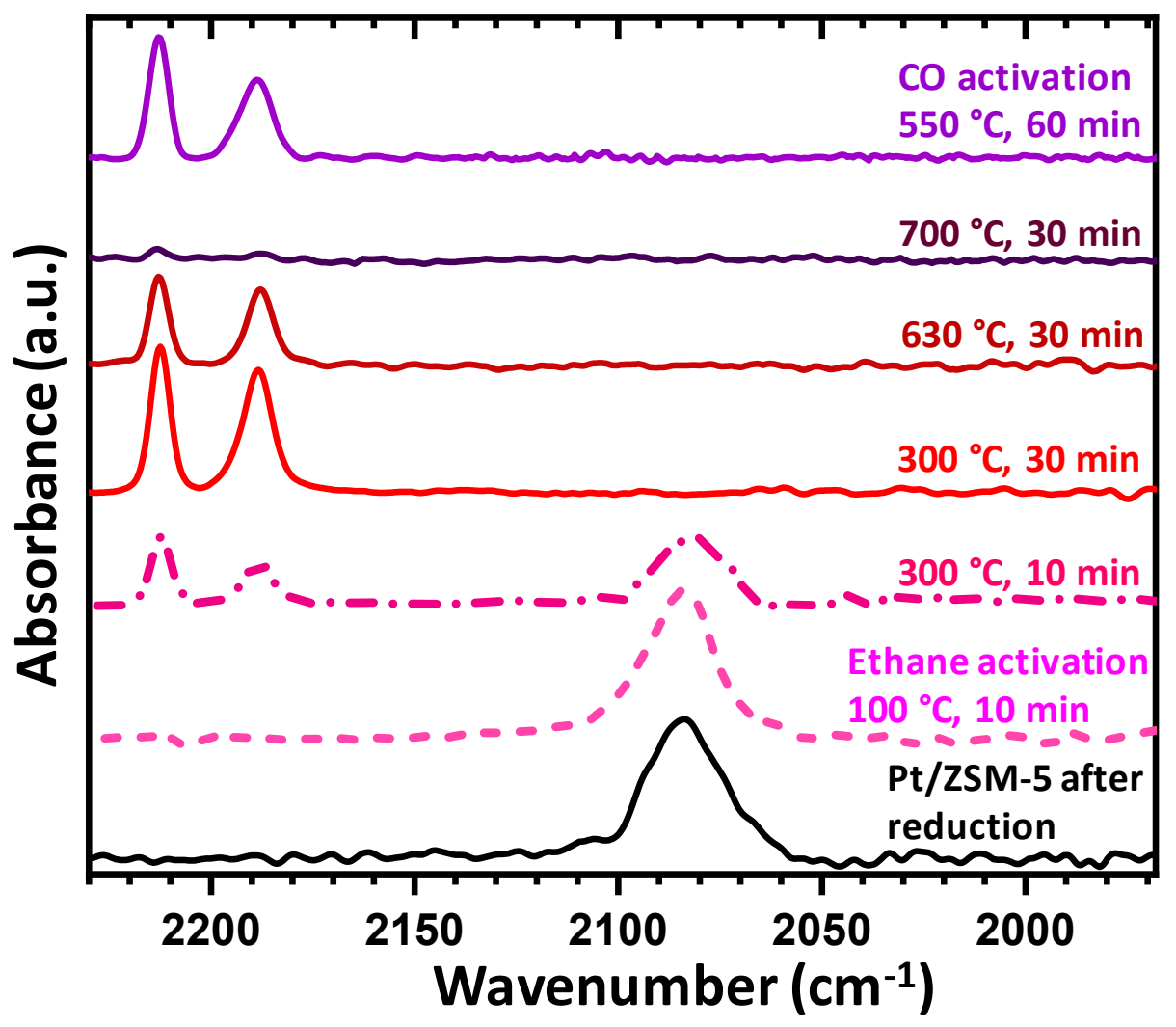

Figure S10. In-situ CO-DRIFT spectra of $0.05 \mathrm{wt} \% \mathrm{Pt} / \mathrm{ZSM}-5$ after reduction, $0.05 \mathrm{wt} \% \mathrm{Pt} / \mathrm{ZSM}-5$ after ethane activation at $100{ }^{\circ} \mathrm{C}$ for $10 \mathrm{~min}, 0.05 \mathrm{wt} \% \mathrm{Pt} / \mathrm{ZSM}-5$ after ethane activation at $300{ }^{\circ} \mathrm{C}$ for $10 \mathrm{~min}, 0.05 \mathrm{wt} \% \mathrm{Pt} / \mathrm{ZSM}$ 5 after ethane activation at $300{ }^{\circ} \mathrm{C}$ for $30 \mathrm{~min}, 0.05 \mathrm{wt} \% \mathrm{Pt} / \mathrm{ZSM}-5$ after ethane activation at $630{ }^{\circ} \mathrm{C}$ for $30 \mathrm{~min}, 0.05$ wt $\% \mathrm{Pt} / \mathrm{ZSM}-5$ after ethane activation at $700{ }^{\circ} \mathrm{C}$ for $30 \mathrm{~min}$, and $0.05 \mathrm{wt} \% \mathrm{Pt} / \mathrm{ZSM}-5$ after CO activation at $550{ }^{\circ} \mathrm{C}$ for $60 \mathrm{~min}$. 


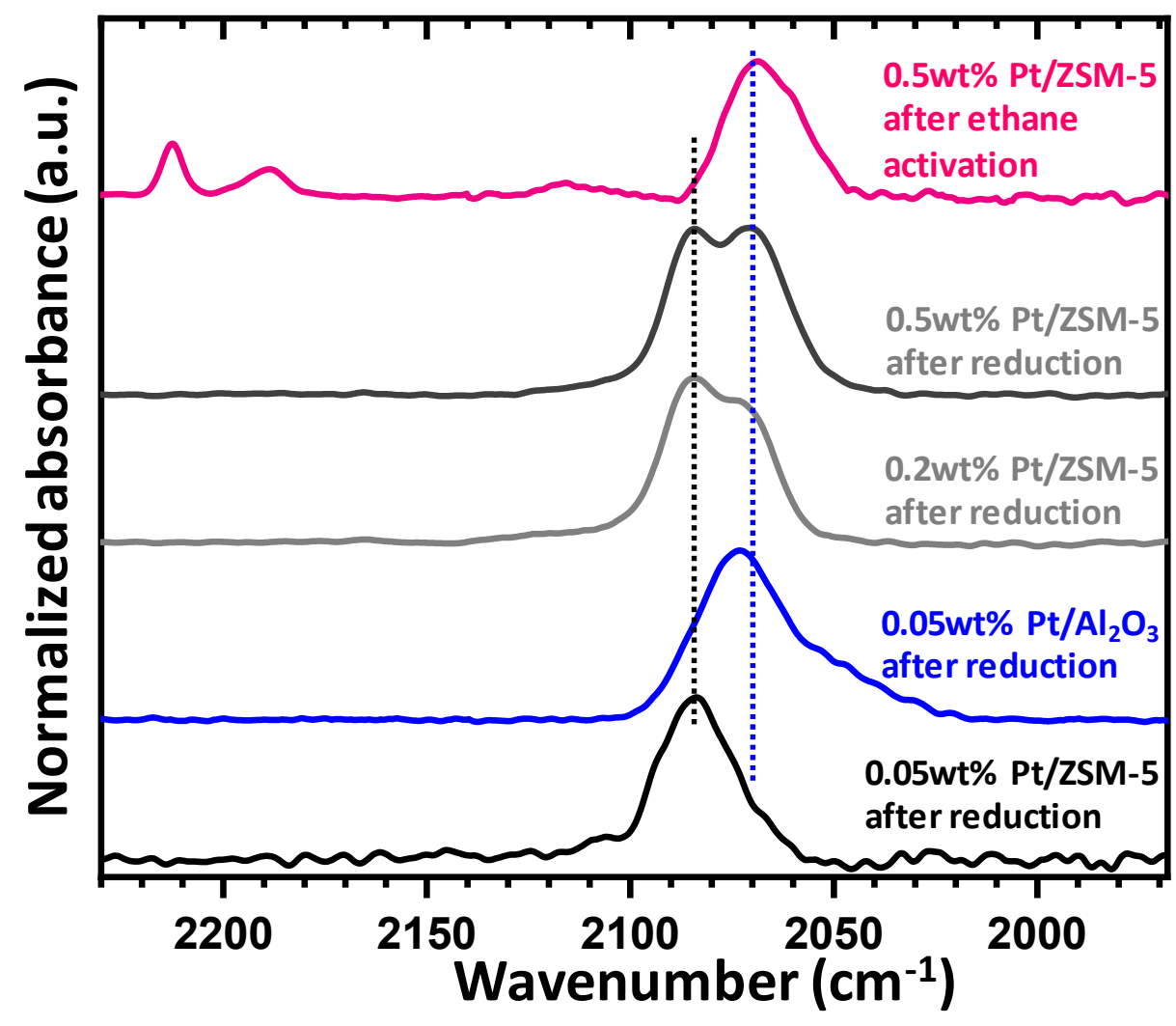

Figure S11. In-situ CO-DRIFT spectra of $0.05 \mathrm{wt} \% \mathrm{Pt} / \mathrm{ZSM}-5$ after reduction, $0.05 \mathrm{wt} \% \mathrm{Pt} / \mathrm{Al}_{2} \mathrm{O}_{3}$ after reduction, 0.2 wt $\% \mathrm{Pt} / \mathrm{ZSM}-5$ after reduction, $0.5 \mathrm{wt} \% \mathrm{Pt} / \mathrm{ZSM}-5$ after reduction, and $0.5 \mathrm{wt} \% \mathrm{Pt} / \mathrm{ZSM}-5$ after ethane activation at $300{ }^{\circ} \mathrm{C}$ for $30 \mathrm{~min}$. 

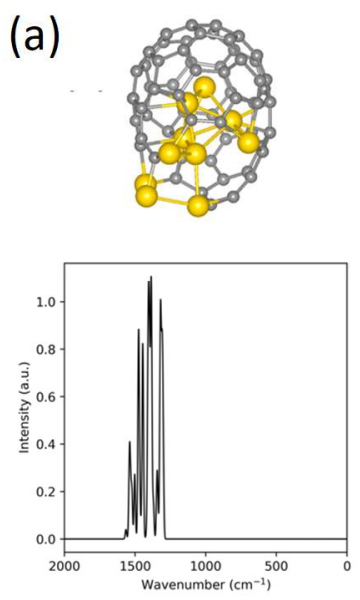

(e)
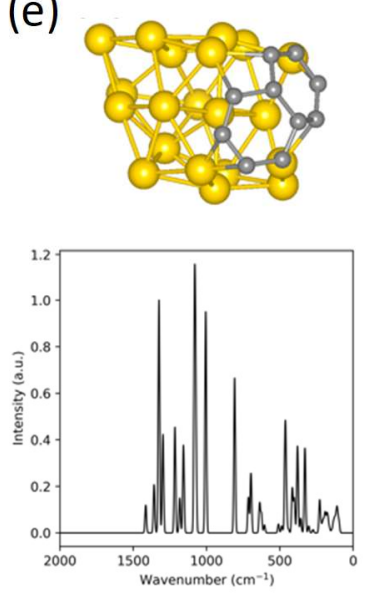

(b)
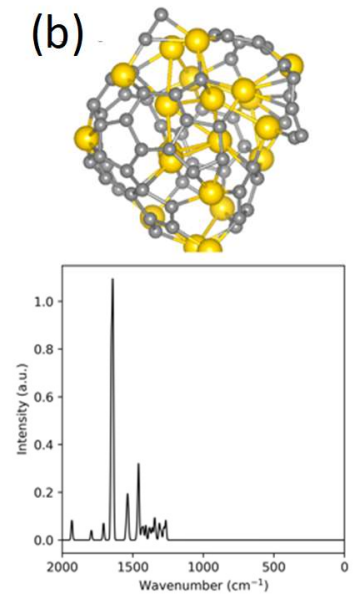

(f)
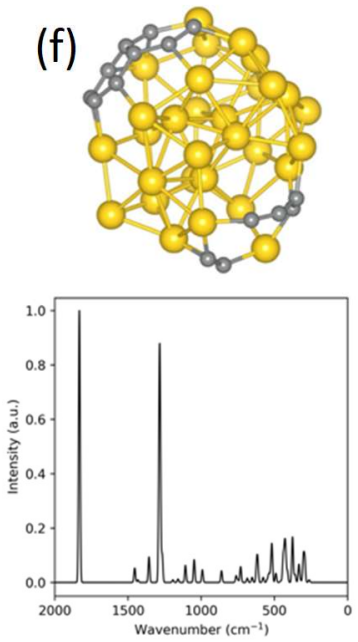

(c)
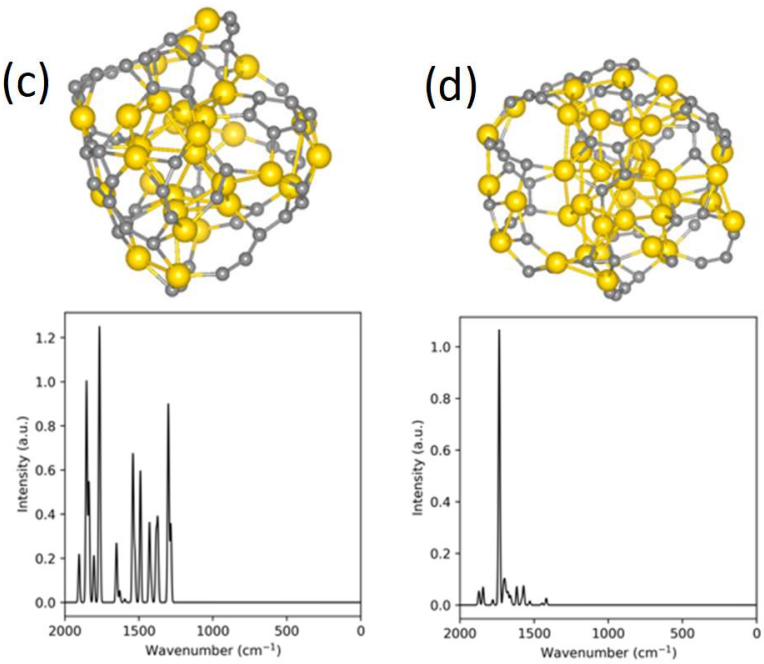

(d)

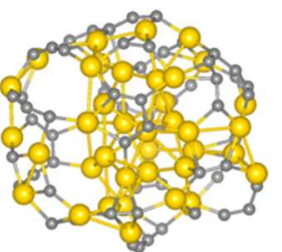

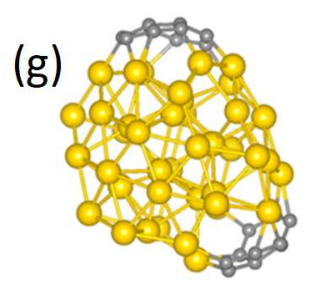

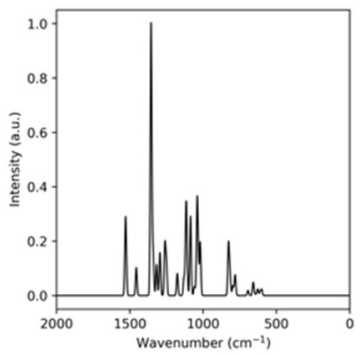

Figure S12. Cluster geometries and calculated IR spectra for (a) $\mathrm{Pt}_{10} \mathrm{C}_{60}$ (core-shell), (b) $\mathrm{Pt}_{20} \mathrm{C}_{60}$ (core-shell), (c) $\mathrm{Pt}_{30} \mathrm{C}_{60}$ (core-shell), (d) $\mathrm{Pt}_{40} \mathrm{C}_{60}$ (core-shell), (e) $\mathrm{Pt}_{20} \mathrm{C}_{10}$ (ring), (f) $\mathrm{Pt}_{30} \mathrm{C}_{15}$ (ring), and (g) $\mathrm{Pt}_{40} \mathrm{C}_{20}$ (ring). 

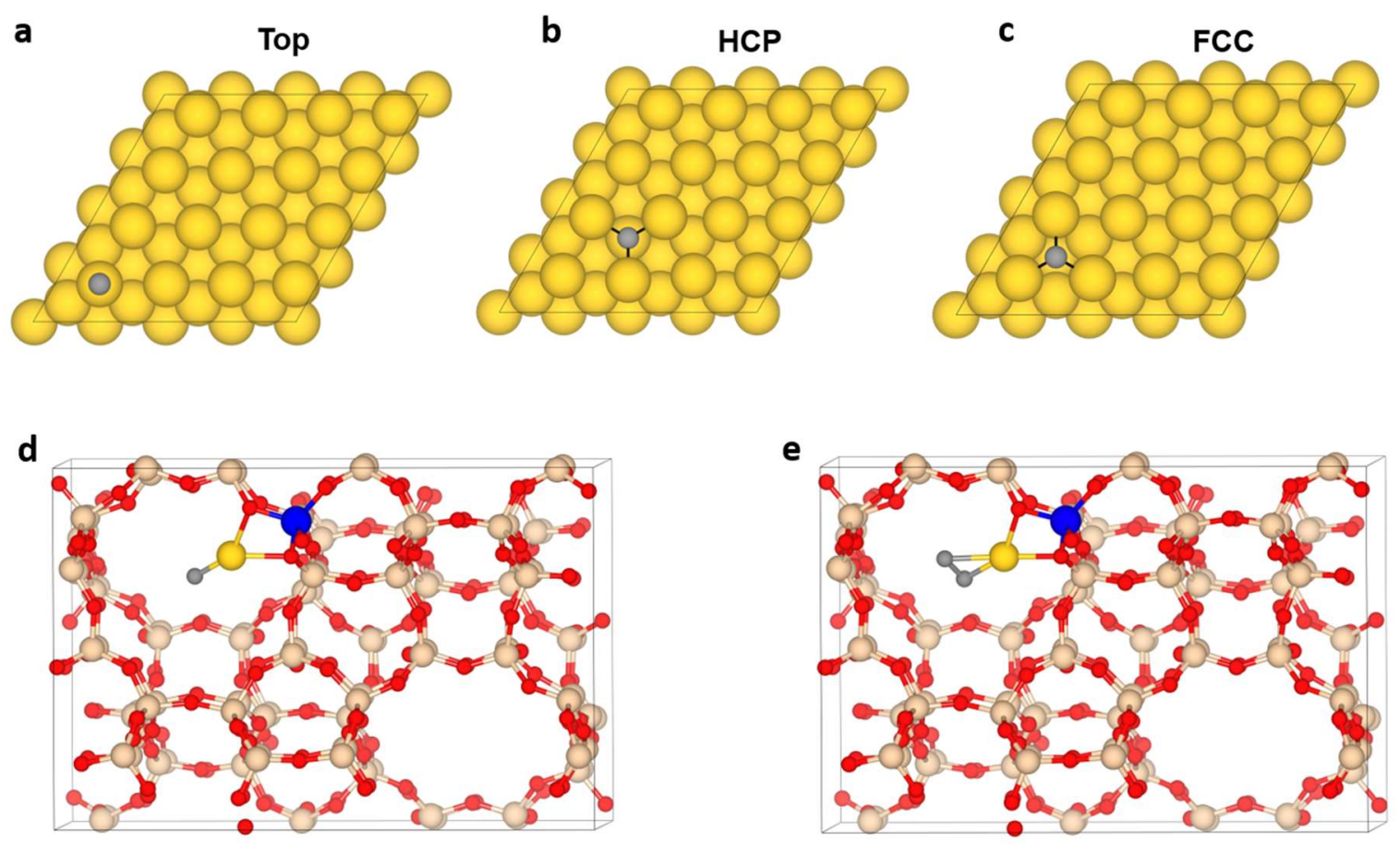

Figure S13. Pt (111) model used in the DFT calculation, as well as the model of C adsorption on isolated single Pt atom supported on ZSM-5. a,b,c, Top view for Pt (111) surface with labels for surface and subsurface adsorption sites. d,e, Optimized structures of one or two C atoms adsorption over single Pt atom supported on ZSM-5. Color code: Pt - gold, C - gray, Al - blue, Si - tan, O - red. 

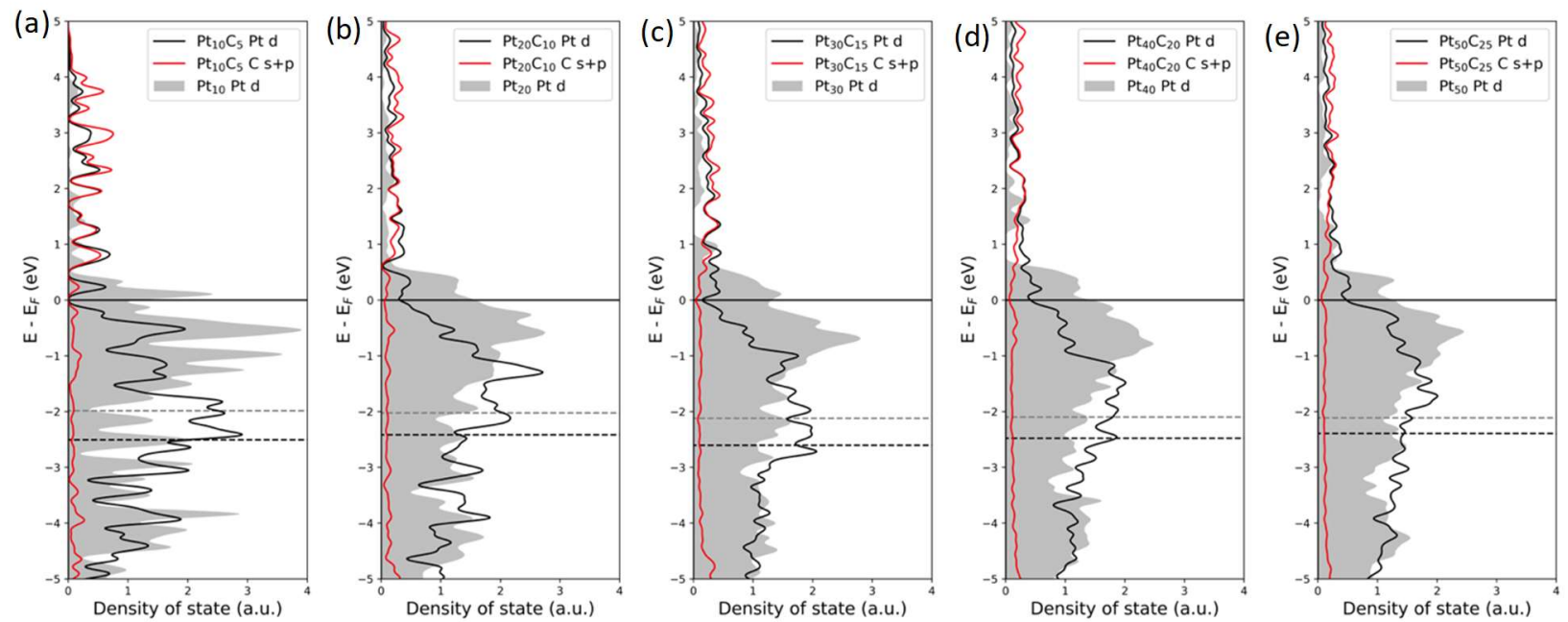

Figure S14. Projected density of states for $\mathrm{Pt}_{\mathrm{x}} \mathrm{C}_{0.5 \mathrm{x}}$ and $\mathrm{Pt}_{\mathrm{x}}, \mathrm{X}=10$ (a), 20 (b), 30 (c), 40 (d), and 50 (e). The horizontal black line, gray dashed line, and black dashed line indicate the Fermi level, the Pt d-band center of Pt $t_{\mathrm{X}}$ clusters, and the Pt d-band center of $\mathrm{Pt}_{\mathrm{x}} \mathrm{C}_{0.5 \mathrm{x}}$ clusters, respectively. 

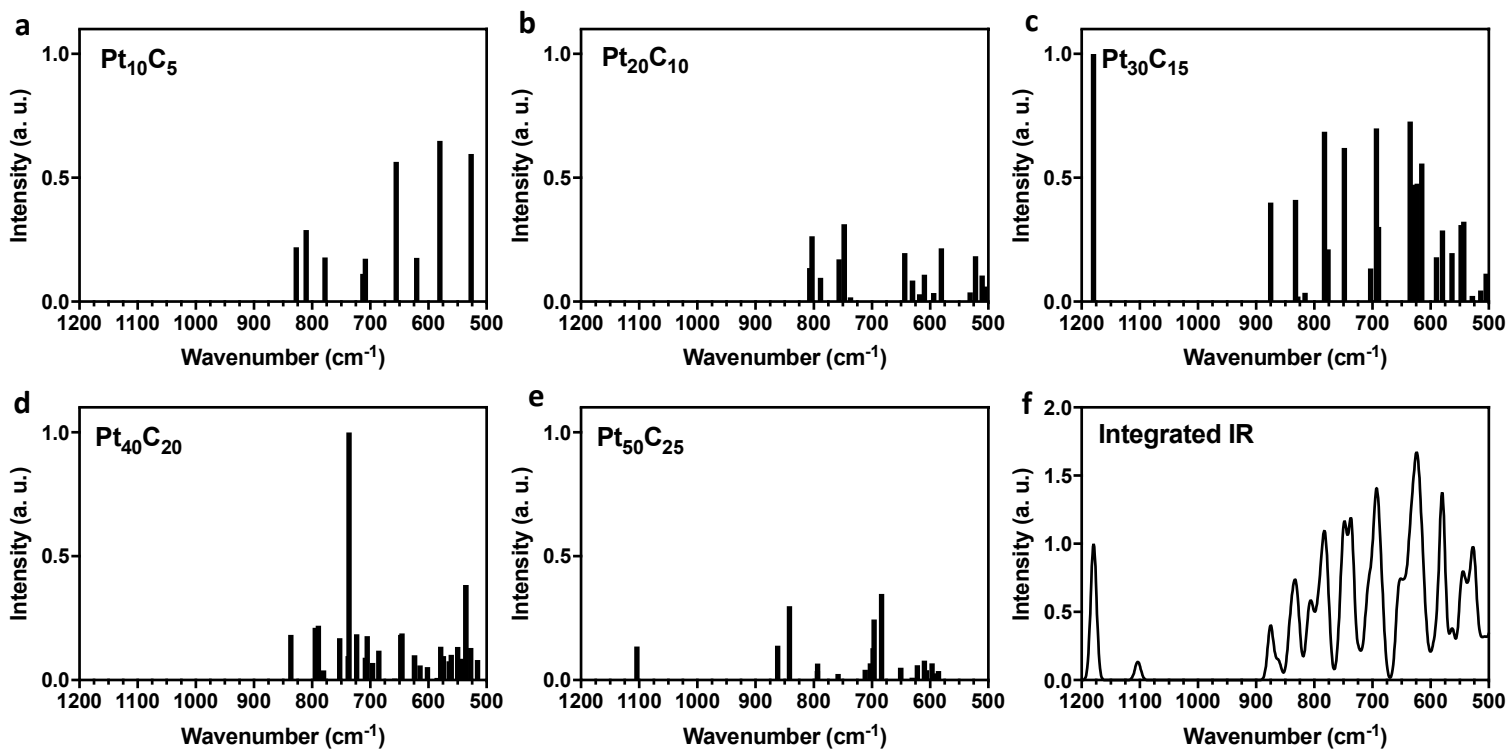

Figure S15. Calculated IR spectra of $\mathrm{Pt}_{2 \mathrm{x}} \mathrm{C}_{\mathrm{x}}(\mathrm{x}=5,10,15,20,25)$ clusters, and integrated spectrum. a,b,c,d,e, Calculated IR spectra of $\mathrm{Pt}_{10} \mathrm{C}_{5}, \mathrm{Pt}_{20} \mathrm{C}_{10}, \mathrm{Pt}_{30} \mathrm{C}_{15}, \mathrm{Pt}_{40} \mathrm{C}_{20}$, and $\mathrm{Pt}_{50} \mathrm{C}_{25}$ clusters, respectively. f, The combined IR spectrum with equal contributions from these five individual IR spectra. Peaks in the combined spectrum were broadened by a normal distribution with standard deviation of $5 \mathrm{~cm}^{-1}$. 

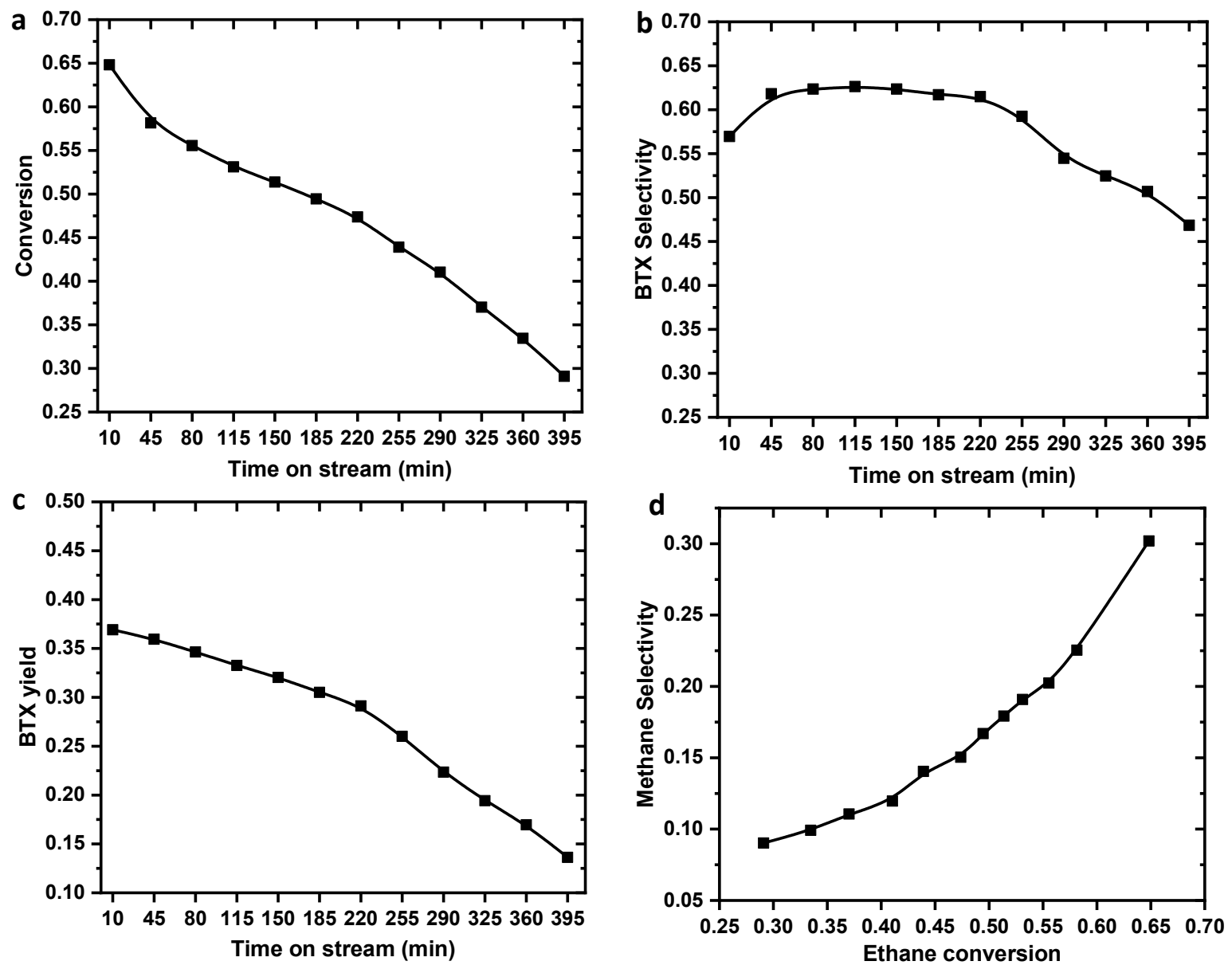

Figure S16. Catalytic performance of $\mathrm{PtC}_{\mathrm{x}} / \mathrm{ZSM}-5$ catalyst in ethane aromatization at $630{ }^{\circ} \mathrm{C}$ and ambient pressure.

a, Ethane conversion as a function of time on stream; b, BTX selectivity as a function of time on stream; $\mathbf{c}$, BTX yield as a function of time on stream; d, Methane selectivity as a function of ethane conversion. Reaction condition: $1 \mathrm{~g}$ of catalyst with Pt loading at $0.05 \mathrm{wt} \%, 1000 \mathrm{~h}^{-1} \mathrm{GHSV}$ of ethane, $630^{\circ} \mathrm{C}$. 


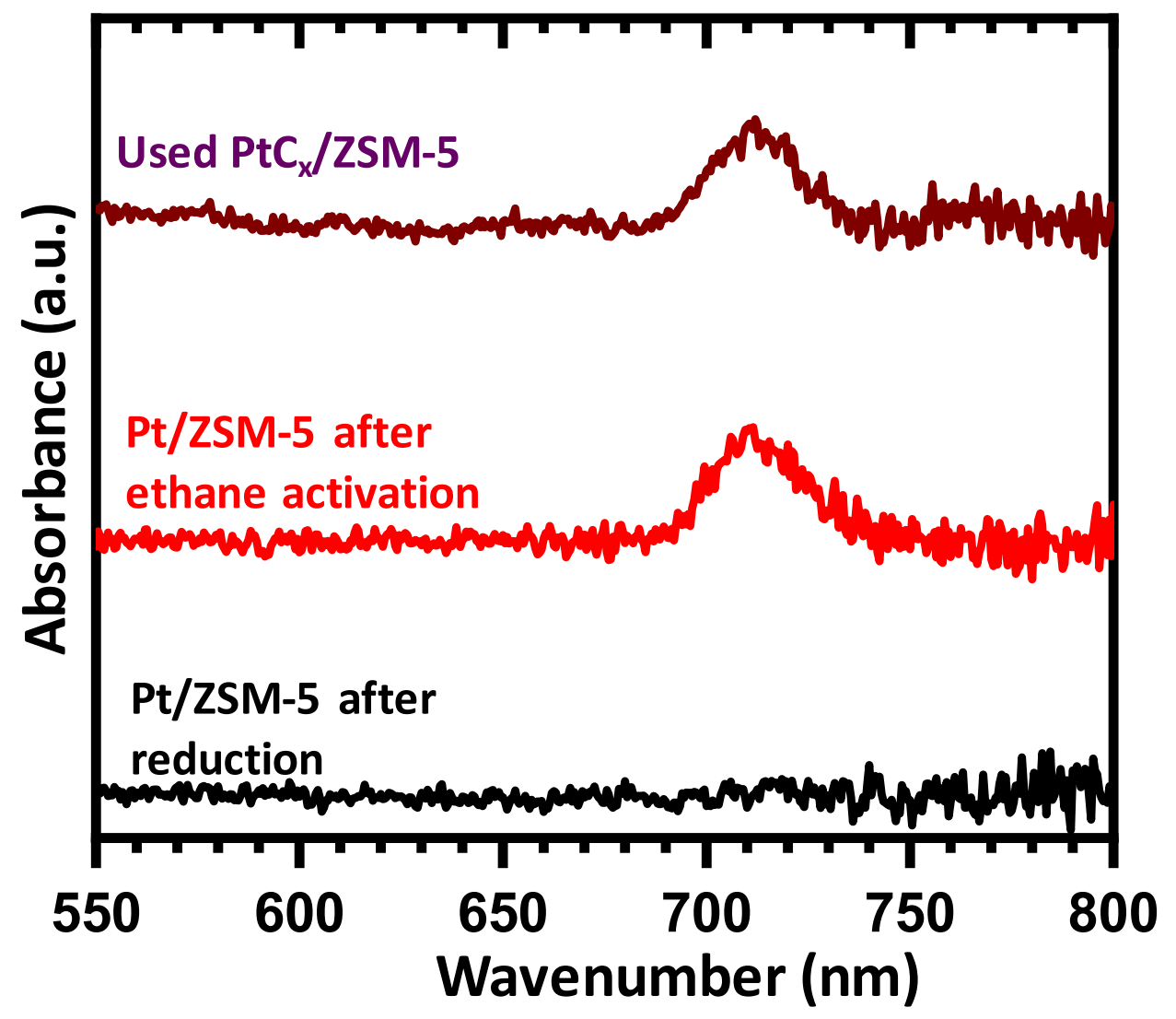

Figure S17. In-situ UV-vis absorption spectra of Pt/ZSM-5 after reduction, and Pt/ZSM-5 after ethane activation, as well as Pt/ZSM-5 after ethane activation and following ethane aromatization reaction at $550{ }^{\circ} \mathrm{C}$ for 2 hours. 


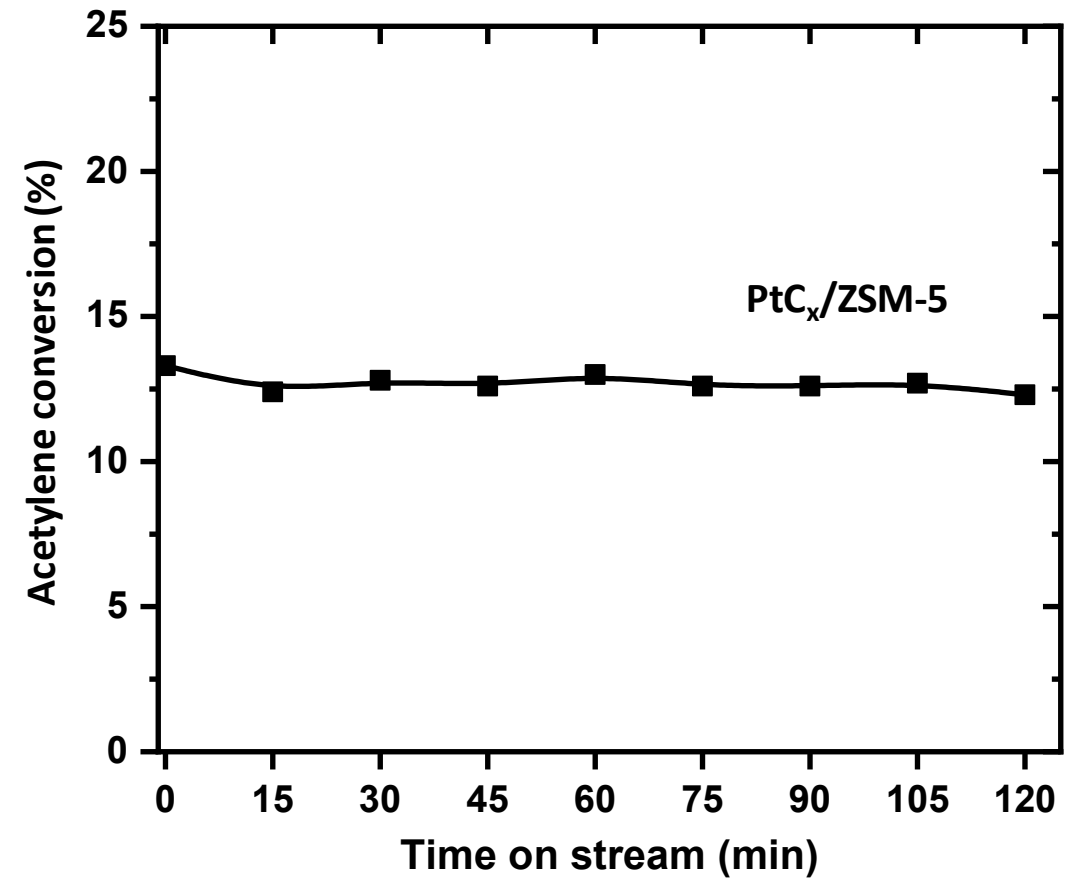

Figure S18. Acetylene conversion on $\mathrm{PtC}_{\mathrm{x}} / \mathrm{ZSM}-5$ at $70{ }^{\circ} \mathrm{C}$ as a function of time on stream in the selective acetylene hydrogenation reaction. 


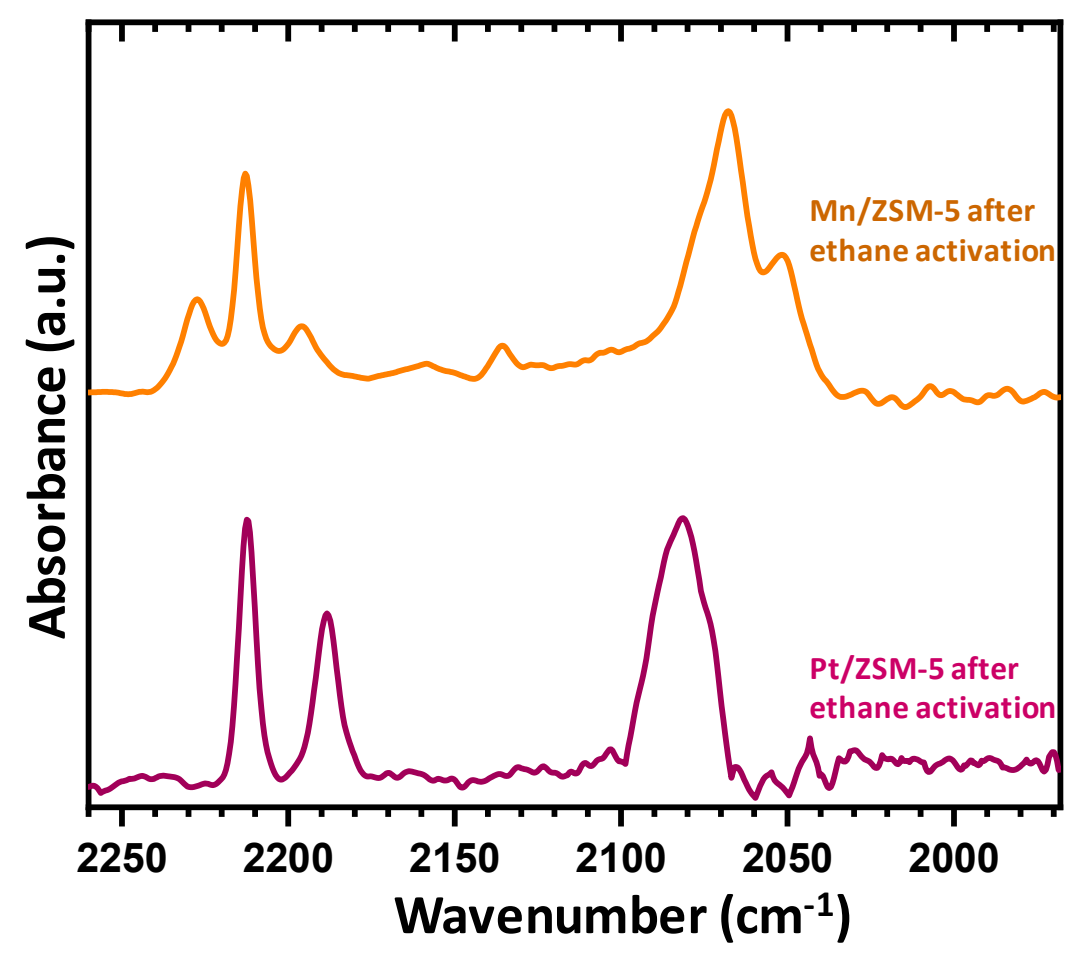

Figure S19. In-situ CO-DRIFT spectra $0.05 \mathrm{wt} \% \mathrm{Mn} / \mathrm{ZSM}-5$ after ethane activation, and $0.05 \mathrm{wt} \% \mathrm{Pt} / \mathrm{ZSM}-5$ after ethane activation. Mn/ZSM-5 sample was reduced with hydrogen at $630{ }^{\circ} \mathrm{C}$ for $1 \mathrm{~h}$, followed by ethane treatment at $650{ }^{\circ} \mathrm{C}$ for $30 \mathrm{~min}$. For comparison, the spectrum of $0.05 \mathrm{wt} \% \mathrm{Pt} / \mathrm{ZSM}-5$ after ethane activation at $300{ }^{\circ} \mathrm{C}$ for $10 \mathrm{~min}$ is also included. 